\title{
Hindered and compression solid settling functions - Sensor data collection, practical model identification and validation
}

Plósz, Benedek G.; Climent, Javier; Griffin, Christopher T.; Chiva, Sergio; Mukherjee, Rani; PenkarskiRodon, Elena; Clarke, Matthew; Valverde Pérez, Borja

Published in:

Water Research

Link to article, DOI:

10.1016/j.watres.2020.116129

Publication date:

2020

Document Version

Peer reviewed version

Link back to DTU Orbit

Citation (APA):

Plósz, B. G., Climent, J., Griffin, C. T., Chiva, S., Mukherjee, R., Penkarski-Rodon, E., Clarke, M., \& Valverde Pérez, B. (2020). Hindered and compression solid settling functions - Sensor data collection, practical model identification and validation. Water Research, 184, [116129]. https://doi.org/10.1016/j.watres.2020.116129

\section{General rights}

Copyright and moral rights for the publications made accessible in the public portal are retained by the authors and/or other copyright owners and it is a condition of accessing publications that users recognise and abide by the legal requirements associated with these rights.

- Users may download and print one copy of any publication from the public portal for the purpose of private study or research.

- You may not further distribute the material or use it for any profit-making activity or commercial gain

- You may freely distribute the URL identifying the publication in the public portal 


\section{Hindered and compression solid settling functions - sensor data} collection, practical model identification and validation

\author{
Benedek G. Plósz ${ }^{1,3,}$, Javier Climent ${ }^{2}$, Christopher T. Griffinn ${ }^{1}$, Sergio Chiva ${ }^{2}$, Rani Mukherjee ${ }^{1}$, Elena \\ Penkarski-Rodon ${ }^{3}$, Matthew Clarke ${ }^{1}$, and Borja Valverde-Pérez ${ }^{3}$
}

\begin{abstract}
${ }^{1}$ Department of Chemical Engineering, University of Bath, Claverton Down, Bath BA2 7AY, UK (Email: b.g.plosz@bath.ac.uk; chris.t.griffin@bath.edu; rm2100@bath.ac.uk;mjc62@bath.ac.uk)
\end{abstract}

${ }^{2}$ Universitat Jaume I, Department of Mechanical Engineering and Construction, Av. Vicent Sos Baynat, s/n 12071 Castellón (Spain),(Email: jcliment@uji.es, schiva@uji.es)

${ }^{3}$ Dept. of Environmental Engineering, Technical University of Denmark, Bygningstorvet, Building 115, 2800 Kgs. Lyngby, Denmark (Email: bvape@env.dtu.dk).

* Corresponding author 

simulations. Results indicate practical model identifiability under well-settling and filamentous bulking conditions.

\section{Keywords}

Hindered and compression solid settling velocity; Compression solid concentration and effective solid stress; settling column sensor; one-dimensional model; computational fluid dynamics (CFD); practical model identification.

\section{INTRODUCTION}

The impact of climate change on influent flow conditions, arising from snow melting and storms events, will require adaptation on the part of water resource recovery facilities (WRRFs) to maintain stringent water quality standards, in the future. The increasing frequency of hydraulic shock events as a result of climate change - necessitates more effective operation and control of secondary settling tanks (SSTs) in WRRFs (Ramin et al., 2014a). Theoretically, the maximum permissible SST loading capacity determines the maximum permissible hydraulic WRRF load. However, the SST capacity varies with activated sludge settleability. As such, stable operation and control necessitates effective sensor technology and identifiable simulation models (Jeppsson et al., 2013; Plósz et al., 2009). Settling sensors should ideally provide experimental data for estimating settling velocity parameters; yet, up to date, no simple and robust methods exist to calibrate hindered and compression settling parameters. Parameter identifiability of activated sludge settling velocity models therefore remains a challenge. Experimental data typically collected during offline sludge settleability monitoring (e.g., sludge volume index) are unreliable (e.g., Wágner et al., 2015) and insufficient means, considering the complexity of settling velocity models. In contrast, De Clercq et al. (2005) present the hitherto most complex observations on solids concentration profiles in batch settling of activated sludge using solids radiotracer and gamma cameras - a technique, whilst capable of revealing hindered and 
compression settling behaviours in high resolution, deemed too expensive to be implemented in WRRFs. To improve data collection, Vanrolleghem et al. (1996) propose recording batch settling curves using a scanner to measure the sedimentation of the sludge blanket over time (SettloMeter). Furthermore, Derlon et al. (2017) present a cost-effective camera-based method to monitor sludge blanket height $(S B H)$. Ramin et al. (2014b) propose a sensor setup with a TSS sensor installed in the bottom of a settling column, thus inferring $S B H$ and the TSS concentration $\left(X_{\text {bottom }}\right)$ time-series. Valverde-Pérez et al. (2017) demonstrate, however, that $S B H$ and $X_{\text {bottom }}$ time-series do not provide sufficient information for reliable identification of the settling velocity model by Ramin et al. (2014b), and propose a novel multi-probe sensor setup, monitoring TSS concentration at multiple heights at the side of the column sensor $\left(X_{\text {side }}\right)$, besides SBH. Despite the extensive experimental data measured, it is still not guaranteed that a unique set of model parameters can be reliably estimated for constitutive functions for hindered and compression settling velocity. Results obtained using state-of-the-art settling velocity models (Li and Stenstrom, 2016; Ramin et al., 2014b) still suggest limitations in terms of practical identifiability of compression settling velocity model parameters. Consequently, besides experimental planning that proposes additional measurements to reduce parameter uncertainties, model reduction is also necessary to adjust model complexity to the information provided in the experimental data. To this end, Guyonvarch et al. (2015) assess the setting of the variable compressive threshold concentration $\left(X_{C}\right)$ parameter using state-of-the-art models (Bürger et al., 2013; Ramin et al., 2014; De Clercq, 2006, De Clercq et al., 2008). Setting $X_{C}$ as a function of the initial solid concentration and the SST feed solid concentration for simulating batch tests and SST, respectively, is found superior over other methods (see also Supporting Information).

In the Bayesian framework, the parameter $\theta$ is treated as a random quantity with a specific prior distribution $p(\theta)$, from which we can obtain the posterior distribution $p(\theta \mid x)$ via Bayes theorem, with $x$ denoting the input data. If the $p(\theta \mid x)$ are in the same probability distribution family as that for the 
$p(\theta)$, the prior and posterior are then called conjugate distributions (Raiffa and Schlaifer, 1961; Bernardo, 2000). Latin-Hypercube-Sampled priors for Simplex (LHSS) is a global approximate Bayesian optimisation method, whereby uniform probability distribution of priors is used (Wágner et al., 2016). One of the criteria for practical model identifiability in LHSS is that $p(\theta \mid x)$ is of normal/Gaussian distribution. The question arises whether, once practical identifiability is established through LHSS, results obtained in terms of uniqueness of normal posterior parameter distribution and mean parameter values for each model structure with the available data series, estimates could be improved by considering normally distributed (conjugate) priors in a subsequent run of parameter estimation - a focal area chosen for this study.

As for the sources of uncertainty associated with settling velocity model identification, the design of settling column setups can significantly influence measured data and thus the parameter estimates (Vanrolleghem et al., 1996; Ekama et al., 1997). More research is still needed to understand how the impact of column size affects model parameter estimates. Therefore, this study also addresses this uncertainty source represented by the approach of using 1-D simulation models for estimating model parameters, which are then used to calibrate CFD simulation models with higher complexity. As for model validation, triangulation is the strategic use of multiple inquiries to address the same question, each depending on different set of assumptions with their strengths and weaknesses (Lawlor et al., 2016). Results agreeing across different inquiries are more likely to be replicated reliably.

The aims set in this study are (1) identifying constitutive functions for hindered-compression settling velocity for which all parameters can be estimated using the sensor data with both good settling and moderate filamentous bulking; (2) evaluating the feasibility of the sensor setup as a means to infer experimental data on the effective compressive solid stress; (3) assessing uncertainty sources associated with the model identification method and the settling column design; and (4) evaluating and validating the new settling velocity constitutive functions using the triangulation approach. 


\section{MATERIALS AND METHODS}

107

108

\subsection{Sampling and settling sensor setup}

Activated sludge samples were collected in two WRRFs in Denmark (Fredericia and Avedøre WRRFs) and one in Sweden (Ellinge WRRF) with well-settling characteristics (Fredericia and Ellinge with $\mathrm{SVI}_{3.5} \leq 90 \mathrm{ml} / \mathrm{g}$ ) and moderate filamentous bulking (Avedøre, $\mathrm{SVI}_{3.5} \sim 200 \mathrm{ml} / \mathrm{g}$ ). The three activated sludge processes differed in terms of operating conditions. Secondary biological treatment in Avedøre WRRF (320 000 PE - mostly municipal sewage) and Fredericia WRRF (350 $000 \mathrm{PE}$ - municipal sewage with significant industrial contribution) were operated at solids retention time, SRT=10-15 days, and used polymers and chlorination for bulking control, respectively. Ellinge WRRF (330 $000 \mathrm{PE}$ - mostly food industrial wastewater) was operated as a high-rate system, SRT 2 days, without any bulking control measure taken. Settling tests were carried out using the multi-probe sensor prototype (Valverde-Pérez et al., 2017), consisting of a column (height: $0.7 \mathrm{~m}$; bottom diameter: $0.2 \mathrm{~m}$ ) equipped with TSS SOLITAX (Hach, USA) infrared sensors installed at $0.21 \mathrm{~m}$ height in the side-wall $\left(X_{\text {Side }}\right)$ and in the bottom of the column $\left(X_{\text {Bottom }}\right)$. Measurements in a full-scale SST were carried in the OBVA WRRF, Vila-Real, Spain (46 773 PE - mostly municipal sewage) was operated at SRT $\sim 10$ days under moderate filamentous bulking conditions $\left(\mathrm{SVI}_{3.5} \sim 270 \mathrm{ml} / \mathrm{g}\right)$ and without any bulking control measure taken. A SOLITAX and a SONATAX (Hach, USA) probes were used to measure the SBH and the TSS in the bottom of the SST, respectively. For measuring the $\mathrm{SBH}$, the threshold TSS concentration was set to $0.3 \mathrm{~kg} \mathrm{~m}^{-3}$. Radial velocity was measured in the 
126

127

128 $D_{\text {Comp }}$ are those shown in Eq. 4 and Eq. 6, respectively. sensor positions in the SST is shown in the SI.

$X_{\text {Bottom }}(t)=f_{X}+\left(X_{\text {Infi }}-f_{X}\right) \cdot\left(1-e^{-k_{X} \cdot t}\right)$,

\subsection{1-D simulation model}

$\frac{\partial X}{\partial t}=-\frac{\partial\left(v_{H}(X) \cdot X\right)}{\partial z}+\frac{\partial}{\partial z}\left(D_{\operatorname{Comp}}(X) \frac{\partial X}{\partial z}\right)$

SST using a Vectrino (Nortek, USA) high-resolution acoustic velocimeter. More information on the

\subsection{Regression analysis to estimate $X_{I n f i}$ parameter}

Values of the maximum solids concentration parameter $\left(X_{\text {Infi, }}, \mathrm{kg} \mathrm{m}^{-3}\right)$ are estimated with the $X_{\text {Bottom }}$ data series (e.g., Fig. 1b) obtained for each settling experiment using the regression equation

in the software, SigmaPlot 13 with $k_{X}$ and $f_{X}$, denoting additional regression parameters.

Solids settling in the column sensor is described as a PDE of second-order parabolic type as

where $X$ is the solid concentration, $z$ is the vertical direction variable, $v_{H}$ is the hindered solid settling velocity, $D_{\text {Comp }}$ denotes the compression settling (Eq. 5). The numerical scheme applied in the simulation model implementation - in MATLAB® (Mathwork, Natick USA) - is according to Guyonvarch et al. (2015). Briefly, the second-order PDE is discretized using 60 layers. The

Godunov approach is used to comply with the minimum settling flux conditions (e.g., Plósz et al., 2007). The height of the sludge blanket is calculated as the distance between the bottom layer and the first layer where the concentration is reduced below $0.9 \mathrm{~g} \mathrm{l}^{-1}$. Constitutive functions for $v_{H}$ and 


\subsection{Practical model identifiability analysis}

A three-level practical identification process (Table 1) was employed in this study, including the (Level 1) assessing the normality (Gaussian) of posterior probability distribution of parameters by employing uniform a priori probability distributions; and (Level 2) re-estimation of posterior parameter distributions using normally distributed (conjugate) priors. Level 3 is carried out to assess the goodness of experimental design and data inferred to achieve practical identifiability.

Level 1 was carried out using the Latin-Hypercube-Sampled priors (250 samples were found sufficient to reach convergence) with uniform a priori probability distributions (LHSS) global method (Wágner et al., 2015). The minimization of the sum of square of relative errors (SSRE), obtained between 1-D model predictions and the experimental results, is carried out using the MATLAB ${ }^{\circledR}$ function fminsearch, employing the Nelder-Mead algorithm - also known as the Simplex method (Nelder and Mead, 1965). For selected constitutive functions with posterior parameter values obtained in narrow, normally-distributed intervals (i.e. Eq. 4 and Eq. 6), posterior parameter probability distributions are re-estimated using LHSS employing normally-distributed priors. Therefore, in Level 2 (Table 1), parameter estimation is carried out by sampling from Gaussian conjugate parameter probability ranges. In the LHSS, the Janus coefficient $(J)$ is used to assess the impact of parameter variability by considering a collinearity threshold for identifiability to be 0.7 (Ramin et al., 2017). This is done by comparing the relative predictive accuracy - calculated as the sum of the root mean square of relative error for $S B H, X_{\text {bottom }}$ and $X_{\text {side }}$ - obtained using the upper and lower parameter boundaries, calculated as the posterior mean parameter values $+/-$ the $95 \%$ confidence intervals obtained. For $J \sim 1$, it is concluded that parameters are uniquely identifiable. Additionally, we report the Akaike's and Bayesian information criteria, AIC \& BIC (Bozdogan, 1987) calculated for the new constitutive functions for hindered and compression settling velocity.
Dynamic global sensitivity (GSA) and uncertainty analysis were carried out using linear regression 
171 of Monte Carlo simulation results obtained in Level 3 (Saltelli et al., 2008; Sin et al., 2011). In the

172 dynamic GSA, values of the standardised regression coefficient $\left(S R C_{j, p}\right)$ is computed for each $\theta_{j}$ and

173 for each output $\left(Y_{k}\right)$ at each time-step using the multivariate linear regression between the $p^{\text {th }}$ LHS

174 sampled parameter value $\theta_{j, p}\left(t_{i}\right)$ and the $k^{\text {th }}$ simulation output $Y_{k}\left(t_{i}\right)$ obtained using Monte Carlo

175 simulations, according to

$176 \quad \frac{Y_{k}\left(t_{i}\right)-\mu_{Y k}}{\sigma_{Y k}}=S R C_{j, p} \frac{\theta_{j, p}\left(t_{i}\right)-\mu_{\theta j}}{\sigma_{\theta j}}+\epsilon_{k}$,

177 including the mean $\left(\mu_{\mathrm{Yk}}\right.$ and $\left.\mu_{\theta \mathrm{j}}\right)$ and standard deviation $\left(\sigma_{\mathrm{Yk}}\right.$ and $\left.\sigma_{\theta \mathrm{j}}\right)$ values of the simulation outputs

178 and parameters, respectively. Furthermore, $\epsilon_{k}$ is the error vector of the regression model (intercept).

179 The coefficient of determination, $\mathrm{R}^{2}$ indicates the proportion of the total uncertainty of the model

180 output explained by the linear model. The SRC values are reliable to be used as sensitivity measures

181 when $\mathrm{R}^{2}>0.6$. Also, only parameters with $\mathrm{SRC}>0.1$ are considered to be influential in predicting a

182 given output. GSA and uncertainty analysis can be used to inform and improve model calibration

183 exercises. Dynamic $S R C_{j, p}$ results were used to assess the sensitivity of predicting different

184 experimental data sets to model parameters and to locate specific experimental periods more

185 conducive to practical identifiability. For more on the calculation of SRC and $\mathrm{R}^{2}$, the reader is referred

186 to Saltelli et al. (2008). In addition to the settling function Eq. 4 and Eq. 6, the 3-parameter (3P)

187 logistic function for hindered settling by Diehl (Diehl, 2015; Torfs et al., 2017) in combination with

188 the compression settling function by De Clercq (2006) - i.e. the so-called Diehl-DeClercq model -

189 was tested through Levels 1-3. Furthermore, the hindered-transient-compression (HTC) settling

190 function by Ramin et al. (2014b) was assessed. The example of the Fredericia sludge (Initial

191 concentration: $3.44 \mathrm{~g} \mathrm{l}^{-1}$; Supporting Information) was chosen as experimental data for benchmarking

192 the different settling functions.

193 For the implementation of the 1-D simulation models and executing simulations the software Matlab

194 (The MathWorks, Inc., http://www.mathworks.com/) was used. Calculations of SRC were carried out 
195

196

197

198

199

200

201

by transferring to and processing simulation results using Python (Python Software Foundation, https://www.python.org/).

\subsection{CFD simulations}

The software ANSYS-CFX ${ }^{\circledR}$ (Academic Res. Release 17.2) was used to implement the solver, according to Ramin et al. (2014b). Briefly, the solver employs an average Eulerian 2-phase flow model. Turbulence is modelled using the k- $\varepsilon$ model. Molecular viscosity of sludge is predicted using the Herschel-Bulkley model (more information on model calibration is shown in the Supporting Information, SI). For the full-scale SST simulations, the solver implementation development included two scenarios, i.e. (1) the novel hindered-compression settling velocity function, (2) simple Vesilind hindered settling function (the model calibration is described in the SI and Fig. S1). The initialization of the 2-day transient state was carried out by converging a previous steady-state case with a constant influent flow. For predicting activated sludge settling in the column sensor, the wall-with-no slip and smooth roughness boundary conditions were used (more information on CFD simulations shown in the SI).

\subsection{Model validation by triangulation (MVT)}

The MVT addresses the question of reliabile prediction of hindered and compression solid settling using the constitutive functions developed. MVT comprises two independent approaches, i.e. (A) practical model identification using two independent sets of laboratory-scale measurements (samples from Ellinge and Avedøre WRRFs) carried out with the new settling sensor setup (Fig. 1) and using the new constitutive functions for hindered-compression settling; and $(B)$ transient-to-steady-state simulations using independent sets of dynamic full-scale measurement data ( $S B H$ and $\left.T S S_{R A S}\right)$ using a CFD simulation model developed. Key sources of bias for approaches $A$ and $B$ are the highly 
degenerated simulation model structure in 1-D and the lack of estimation of parameter values other than settling velocity parameters through the calibration of the CFD simulation model, respectively. No specific direction of bias of these sources can be explicitly identified. Results from these two approaches are then compared through the 3-D CFD simulation of column tests for well-settling and filamentous sludges in terms of $S B H, X_{b o t t o m}$ and $X_{\text {side. }}$.

\subsection{Assessment of two sources of uncertainty}

226 One of the sources of uncertainty assessed using CFD simulations, involved the design boundary conditions of the settling column setup, characterised with a design factor $(F)$. The impact of the column sensor design on the model parameter estimates was tested via CFD simulations, whereby the CFD solver was calibrated with model parameters obtained for the Fredericia sludge at $3.44 \mathrm{~g} \mathrm{l}^{-1}$ as initial concentration and for the Avedøre sludge at $3.86 \mathrm{~g}^{-1}$ as initial concentration. The base case scenario $(\mathrm{F}=1)$ was that of the real setup (Fig. 1a), and factors (e.g., $\mathrm{F}=0.7$ means $70 \%$ ) were applied to resize the height and diameter of the column - maintaining the original proportions - using five scenarios. Additionally, the approach of using 1-D simulation models for estimating parameters using batch experimental data - that are then used to calibrate CFD simulation models - was identified and assessed as an additional uncertainty source. The uncertainties in parameter values introduced as a result of using different settling column designs were quantified using CFD simulations by considering the settling characteristics of the Fredericia and Avedøre sludge samples at $\mathrm{X}_{\mathrm{ini}}=3.44$ and $3.9 \mathrm{~g} / 1$ as initial concentrations, respectively. 3-D profiles obtained were converted into 1-D concentration profiles that were then used to re-estimate the posterior model parameter values. The posterior parameter estimates were then benchmarked against that obtained using the 1-D simulation model and the column sensor measurement data. 


\section{RESULTS AND DISCUSSIONS}

\subsection{Practical model identification}

An iterative approach was taken to test the practical identifiability of parameters in a plethora of potential rate equations (more information shown in SI). Using practical identifiability as a selection criterion, a four-parameter model was identified to describe hindered-compression settling as

$v_{S}=\left\{\begin{array}{cc}v_{H}(X)=v_{0} e^{-r_{H} \cdot X} & 0 \leq X \leq X_{C} \\ v_{H}(X) \cdot\left(1-\frac{\rho_{S}}{\left(\rho_{S}-\rho_{f}\right) g X} \frac{\partial \tau}{\partial X} \frac{\partial X}{\partial z}\right) & X>X_{C},\end{array}\right\}$,

252 where

\subsubsection{Hindered-compression settling velocity functions}

$D_{\text {Comp }}=\left\{\begin{array}{cc}0 & 0 \leq X \leq X_{C} \\ v_{H}(X) \frac{\rho_{S}}{\left(\rho_{S}-\rho_{f}\right) g X} \frac{\partial \tau}{\partial X} & X>X_{C}\end{array}\right\}$

254 with

$255 \frac{\partial \tau}{\partial X}=v_{C} e^{\left[r_{C} \cdot \frac{X}{X_{I n f i}}\right]}$,

256 where the effective solids stress $(\tau)$ derivative is formulated using an exponential term with $v_{C}\left(\mathrm{~m}^{2}\right.$

$\left.257 \mathrm{~s}^{-2}\right)$ and $r_{C}(-)$ parameters. The maximum solids concentration $\left(X_{\text {Infi }}, \mathrm{kg} \mathrm{m}^{-3}\right)$ is used to normalise 258 local biomass concentration values, $X$. For hindered settling velocity $\left(v_{H}, \mathrm{~m} \mathrm{~s}^{-1}\right)$, the model includes 259 a pseudo 2-parameter exponential constitutive function with $v_{0}\left(\mathrm{~m} \mathrm{~s}^{-1}\right)$ and $r_{H}\left(\mathrm{~m}^{3} \mathrm{~kg}^{-1}\right)$, denoting the 260 hindered settling velocity parameters. In Eq. 4, $\rho_{S}$ and $\rho_{f}$ are the sludge and water density, 261 respectively; $g$ denotes the gravitational acceleration constant; $z$ is the depth in the settling column.

262 The setting of the compressive threshold concentration $\left(X_{C}\right)$ is according to Guyonvarch et al.

263 (2015). That is, for simulating batch column tests, 1-D advection-dispersion and 2-D CFD

264 modelling of SSTs, $X_{C}=X_{\text {ini }} ; X_{C}=X_{\text {feed }+1}$ and $X_{C}=X_{\text {feed }}$, respectively; where $X_{\text {feed }+l}$ is the solid 
concentration located just below the dynamic feed-layer in 1-D simulation model, and $X_{\text {feed }}$ is the solid concentration in the SST influent.

Compared to previous models, including the exponential term (Vesilind, 1968; Takács et al., 1991), instead of letting parameters independently vary, the ratio of $v_{0} / r_{H}$ is estimated with $v_{0}$ set as constant at $v_{0}=0.0025\left(\mathrm{~m} \mathrm{~s}^{-1}\right)$. The $v_{0} / r_{H}$ ratio $\left(\mathrm{kg} \mathrm{m}^{-2} \mathrm{~s}^{-1}\right)-$ same unit as solid flux - can be linked to the degree of sludge bulking (Ekama et al., 1997; Wágner et al., 2015), making it a suitable controlled variable at WRRFs. Previous experimental studies (Daigger, 1995; Weiss et al., 2007) also indicate a constant $v_{0}$. In fact, Daigger's database show a value $\left(0.0022, \mathrm{~m} \mathrm{~s}^{-1}\right)$ that is in very close agreement with our observations obtained through practical model identification, thereby providing experimental evidence to consider $v_{0}$ as constant.

The new settling velocity functions require the estimation of three parameters $\left(v_{0} / r_{H}, v_{C}, r_{C}\right)$ using global optimisation and the parameter, $X_{\text {Infi }}$ is directly deducible from experimental data using regression analysis. Uncertainty plots (Fig. 2a) show 95\% confidence intervals effectively covering most of the measured data. Values of relative dynamic sensitivity (Fig. 2c) and coefficient of determination (Fig. 2d) suggest potential benefits of the set of experimental data for parameter identifiability: high sensitivity of predicting SBH and TSS side sensor concentration data to $v_{0} / r_{H}$ parameter. Moreover, the prediction of TSS bottom and side concentration data show relatively high sensitivity to the compression settling parameters, $r_{C}$ and $v_{C}$. Based on the trajectories of SRC, an extended experimental time beyond one hour does not seem to add any significant benefit to parameter estimation. That is SRC does not increase significantly beyond the experimental time set in here. Posterior parameter distributions (Fig. 3) show comparably narrow confidence intervals (CI), i.e. CI-to-mean parameter ratios are $<50 \%$ (Supporting information). Although, the covariance matrices show values up to $\sim 0.83$ for compression parameters, parameter variability does not significantly influence simulation outputs, i.e. $J \sim 1$ obtained, thereby indicating practically 
identifiability of model parameters using the experimental data. Additionally, increasing the initial solids concentration increases the SRC values only for $v_{0} / r_{H}$ parameter (Fig. S2-S5) - whilst no significant benefits in terms of identifiability of compression parameters can be drawn. Part of the reason for this observation may stem from the position of the side sensor - perpendicular to the direction of the settling solids in the column - that can possibly lead to deteriorating quality of sensor data, in particular, at higher solid concentrations (e.g., Fig. S5). This shortcoming of the sensor; however, does not seem to influence the overall quality of unique parameter sets obtained, i.e. mean values of $v_{0} / r_{H}, v_{C}, r_{C}$ are obtained with relatively narrow ranges of mean parameter values and with overlapping 95\% confidence intervals (Fig. 3) - except for the lowest $r_{C}$ value obtained with filamentous bulking sludge. Therefore, to improve parameter identifiability, future research should, focus on optimising the position of the side sensor. In addition to Eq. 4 and Eq. 6 functions, the DiehlDeClercq and the HTC models were assessed, and were found practically non-identifiabile based on Step 6a \&6b@Level 1 (Table 1, Supporting Information). That is, for the Diehl-DeClercq functions, histograms obtained (Step 6a@Level 1) indicate non-identifiability for vo, $q, \alpha$ (Supporting Information). Comparably high SRC values were obtained only for $v_{0}, \bar{X}$ and $C_{g}-$ an outcome that reasonable agrees with the parameter identifiability results (Level 1), except for $v_{0}$ for which high SRC values do not result in identifiability. Relatively high parameter correlation is found for $v_{0}-\bar{X}$ and $\bar{X}-C_{g}$ parameter pairs (Janus test not done). For the HTC functions, histograms obtained (Step 6a@Level 1) indicate non-identifiability for $r_{H}, C_{1}$ and $C_{2}$ (Supporting Information). Comparably high SRC values were not obtained for any of the parameters, thus indicating major limitations of practical identifiability. Relatively high parameter correlation is found for $v_{0}-\bar{X}$ and $\bar{X}-X_{C}$ parameter pairs (Janus test not done). Despite failing the identifiability criteria, to provide a comparison between different settling functions, AIC and BIC values (Table 2) were also computed for the Diehl-DeClercq and the HTC functions. Based on the information criteria, the strength of the evidence (e.g., $\Delta \mathrm{BIC}$ ) 
313

314

against the functions with the higher BIC value is reasonably strong, i.e. $\Delta \mathrm{BIC}>6-10$ (Kass and Raftery, 1995).

\subsubsection{Modelling compression settling}

The present paper proposes a compression settling function to predict any effects of solid stress propagating through the sludge blanket (i) by setting $X_{C}=X_{I n i}$ and (ii) by formulating the solids stress, in contrast to previous approaches, independently from the $X_{C}$ value and from the relative concentration $\left(X-X_{C}\right)$. DeClercq (2006) suggest modelling sedimentation transport by considering hindered and compression settling, and by employing a time-dependent onset of compression through $X_{C}$. Partly because DeClercq (2006)'s model overestimate the transient settling velocity (in the falling hindered settling rate region characterised with straight isoconcentration lines) and due to challenges in implementing the proposed $X_{C}$ models in SST simulation models, Ramin et al. (2014) propose a model that additionally (A) includes a first-order transient settling function, formulated analogously to hindered settling, and (B) employes two threshold concentrations for the onset of transient $\left(X_{T}\right)$ and for compression settling, $X_{C}$.

In Fig. 4a, at relatively low $X$ values, upward propagating straight isoconcentration lines are shown, above which, tangential isoconcentration lines propagate from the sediment-suspension interface. These simulation results demonstrate the consistency of the simulation model with the actual physical phenomena, i.e. with theory (Diplas and Papanicolaou, 1997, Kinnear, 2002) and experimental observations (DeClercq et al., 2008 - the Destelbergen sludge). There is also a close agreement between the evolution of the effective solid stress derivative obtained with the Destelbergen sludge (DeClercq et al., 2008) - i.e. $0.25-1.95 \mathrm{~m}^{2} \mathrm{~s}^{-2}$ for $X_{\text {ini }}=2.4,3.2 \mathrm{~g}^{-1}-$ and that shown in this study (Fig. 10). With well-settling solids (Fig. 4b,c), isoconcentration lines indicate a comparably fast compressive solid consolidation behaviour compared to that obtained with filamentous sludge (Fig. $4 a)$. 
Additionally, the physical justification for setting $X_{C}$ at the feed solid concentration for SST modelling (Guyonvarch et al., 2015) is that the density current of the feed slurry tends towards zero buoyancy, thus propagating through volumes, under which, the descending particles shall increase the local concentration only if they exhibit compressive solids settling. For more information, the reader is referred to the Supporting Information.

\subsection{Model validation}

\subsubsection{Independent batch settling experiments}

Independent experimental settling data - obtained using solids with well-settling (Ellinge WRRF) and filamentous bulking (Avedøre WRRF) characteristics - were used to test the practical identifiability and the validity of the simulation model, including the new hindered-compression settling functions. As for the Ellinge data (Fig. S6-S8), results obtained show close agreement with the outcomes in the Fredericia case (Fig. 2) in terms of predictive accuracy for SBH, TSS $_{\text {side, }}$ TSS $_{\text {bottom }}$ sensor data outputs and of parameter covariance. Parameter covariance obtained with the comparably narrow probability density ranges (Fig. S6-S8; covariance indices up to $\sim 0.8$ for $v_{C}$ and $r_{C}$ ) does not significantly influence simulation outputs, i.e. $J \sim 1$. However, the uniqueness of $v_{C}$ parameter estimates is not significantly impacted (Fig. 3). Values of SRC $>0.8$ values for both $v_{0} / r_{H}$ and $r_{C}$ indicate high sensitivity of model predictions to both parameters that can potentially benefit practical model identifiability (Fig. S6-S8). In contrast to the Ellinge dataset, prediction of settling of solids collected in Avedøre WRRF extends the validity of the simulation model to filamentous bulking conditions (Fig. 5; Fig. S9-S12). Again, the outcomes of the identifiability test closely agree with the Fredericia and Ellinge cases. Disparities to the Fredericia and Ellinge cases, include the improved prediction of the SBH and TSS bottom with bulking sludge, whereas the accuracy of $\mathrm{TSS}_{\text {side }}$ prediction is compromised at both low and high initial solids concentrations (Fig. 5a,d). Finally, according to 
the increasing values of SRC for compression settling parameters for $\mathrm{TSS}_{\text {side, }}$ under filamentous bulking conditions, practical identifiability tests may benefit from extending the length of experiment over an hour at low initial solids concentration, i.e. $<3.3 \mathrm{~g} \mathrm{~L}^{-1}$ (Fig. S11). In terms of uniqueness of posterior parameter estimates (Fig. 3), the identifiability of compression settling parameters seems to be compromised at higher initial solids concentrations - possibly, as a result of wall-effects - though, this effect is not significant, based on the confidence intervals obtained (Fig. 3).

Taken together, the independent results obtained with Ellinge and Avedøre solids suggest the validity of the identifiability approach and the simulation model structure for well-settling and filamentous structures for WRRFs.

\subsubsection{CFD simulations of a full-scale SST}

As part of the MVT approach, forward CFD simulations were carried out to validate the hinderedcompression settling model. Simulations of the SBH, $X_{R A S}$ reasonably agree with the measured fullscale SST data collected during more than 40 hours (Fig. 6a and 6b). Furthermore, radial velocity measurements (see also SI) indicate close agreement with that predicted using the new settling velocity model. We note that CFD model prediction is somewhat compromised when predicting the transient SST behaviour - in terms of SBH and TSS $_{\text {RAS }}$ between maximum and minimum loading conditions (between 20 and 30 hours). It is assumed that the lack of undertaking a more in-depth optimisation of the e.g., SBH sensor calibration, CFD simulation model can explain the prediction inefficiency observed.

Taken together, both approaches involved in the MVT support the hypothesis that the novel constitutive functions for hindered and compression settling velocity combined with the $X_{C}$ setting method can reliably predict the real physical phenomena. 


\subsection{Posterior parameter estimation and parameter intervals}

Fig. 3 summarises all parameter values with confidence intervals obtained with the sludge samples taken from the three WRRFs. As for Fig. 3a., fixing $v_{0}$ was found to allow the estimation of $v_{0} / r_{H}$ values in a narrow range (Fig. 3) for the different initial concentrations and independently from the compression parameters. This was otherwise impossible to achieve with any of the hindered and compression functions and their combinations thereof tested (see more on this in the SI). Fig. 3a also supports the hypothesis of $v_{0} / r_{H}$ effectively gauging sludge settling properties (Wágner et al., 2015). Furthermore, an arbitrary threshold value $v_{0} / r_{H} \sim 0.005$ is proposed to distinguish between wellsettling and filamentous bulking solids. Despite the considerable difference between the three WRRFs in terms of operating conditions - notably, SRT and bulking control measures - all four settling velocity parameters obtained show consistent and comparable trends. That is, hindered and compression parameters are independent of initial solids concentration and the parameter values obtained for well-settling solids versus filamentous bulking sludge vary significantly at low initial solid concentrations. In the practical identification analysis (Level 1), posterior values of mean \pm confidence intervals obtained (Table 1; Fig. 7) suggest the dependence of most compression parameter sets on the initial solid concentration - a possible physical phenomenon, agreeing with that reported in literature (Ramin et al., 2014b; DeClercq et al., 2008). Furthermore, once practical identifiability of model parameters is established through Level 1 (Table 1), Gaussian conjugate priors are used in Level 2 (Table 1; Fig. 3). Posterior parameter estimates obtained in Level 2 indicate the independence of hindered $\left(v_{0} / r_{H}\right)$ and compression settling parameters $\left(v_{C}\right.$ and $\left.r_{C}\right)$ of the initial solids concentration, thereby suggesting the effect, being a result of error propagation rather than of real physical phenomena. 


\subsection{Practical guidance on sensor application for parameter}

\section{estimation}

The settling column sensor application presented here has clear benefits and shortcomings. On the one hand it can be used to infer data for practical identification and parameter estimation of the constitutive function (Eq. 4 and Eq. 6). The results (Fig. 2, Fig. S2-S12) indicate the benefits of using the bottom- and the side-TSS sensors to decrease the uncertainty of $r_{C}$ and $v_{C}$, compression parameters. This however, is only true at comparably low initial solid concentrations. On the other hand, low parameter variability is obtained for all settling velocity parameters in the initial solid concentration range examined (Fig. 3). Consequently, from a practical point of view, employing the column sensor setup in 1 or 2 batch experiments - at initial solid concentrations $\leq 3 \mathrm{~g} \mathrm{~L}^{-2}-$ to infer data for parameter estimation seems reasonable and a reliable way of settling parameter estimation.

\subsection{Assessing sources of uncertainty using CFD simulations}

For selected initial solids concentrations with well-settling and bulking sludge, the close agreement of measured and CFD simulation results (Fig. 8 at design factor $\mathrm{F}=1$ ) indicate negligible uncertainties introduced by the 1-D parameter estimation approach, and thus suggest the reliability of the parameter estimation approach. Interestingly, compared to the 1-D case (compare Fig. 8a-c to Fig. 2), closer agreement between the simulated and measured SBH data is achieved using the CFD simulation model. This result suggests that the overestimation of the compressive SBH tail by the 1-D simulation model may be a bias caused by the degenerated 1-D simulation model structure rather than the settling velocity model structure - an impact that will be investigated in the future. The latter was the same in both the 1-D and the 3-D CFD model. Torfs et al., (2017) assessed the effect of overestimation of the compressive SBH tail in more depth, suggesting the 1-D simulation model structure - in terms of 
hindered settling velocity formulation - as the potential cause of this bias. Furthermore, to assess the variability of parameter values as a result of settling column design, CFD simulations, carried out within a wide range of column design boundary conditions (Fig. 8), were used to re-estimate the posterior model parameter values (Fig. 9). Results obtained suggest that, assuming negligible wall effects in the column sensor, the estimated $r_{C}$ values can be expected to vary significantly in the design boundary range studied for both well-settling and filamentous sludge settling. However, it is not expected to introduce significant bias in the predictive accuracy based on $J \sim 0.91$ obtained using the 1-D simulation model calibrated with the lowest and highest values obtained for $r_{C}$ (Fig. 9).

\subsection{Quantifying the effective solid stress derivative using sensor}

\section{data}

This study also addressed the question whether the multi-probe sensor setup could be used to quantify the $\tau$ derivative - a variable approximated using the sensor data according to

$\frac{\partial \tau}{\partial X}=\frac{\left(\rho_{S}-v_{L}\right) \cdot g \cdot h_{\text {side sensor }}}{X_{\text {Bottom }}(t)-X_{\text {Side }}(t)}$,

where the density difference between water and sludge $\left(\rho_{s}-\rho_{L}\right)$ was assumed constant. Eq. 7 was formulated based on force balance analysis - assuming only the gravitational, buoyancy and solids pressure acting on particles - and by assuming quasi steady-state conditions (Xu et al., 2017). Simulation results obtained (Fig. 10) reasonably agree with the sensor $\tau$-derivative values for sludge with well-settling and filamentous bulking characteristics, thereby indicating the feasibility of the sensor approach to quantify the solid stress derivative. This outcome is extremely important as it indicates that the sensor setup presented herein can be used by practitioners to estimate compression settling parameters directly from the measurements using simple regression analysis - similar to that conventionally used for hindered settling parameter estimation. To test the approach $v_{C}$ and $r_{C}$ values were estimated using exponential curve fitting of the $\tau$-derivative $-X / X_{\text {infi }}$ (Fig. 10). Discrepancies 
between $v_{C}$ and $r_{C}$ values obtained and those estimated through global optimisation (Fig. 3) are between $4-260 \%$. The fitness of settling model calibration by means of simple regression analysis should be evaluated, in the future, thereby also assessing the error introduced by assuming quasi steady-state in approximating compressive solids stress using the sensor data.

De Clercq et al. (2008) present a study of calculating solids stress in settling column tests carried out with the aid of radiotracers. These tests allow the spatial-temporal quantification of complete concentration profiles. In contrast, our setup offers a simpler cost-effective technical solution for practitioners with temporal TSS measurements only at two spatial points. In our study, in contrast to De Clercq (2006), estimating the solids stress gradient and employing $X_{C}$ fixed at the initial concentration allowed the implementation of constitutive functions with reduced complexity and number of parameters.

\section{OUTLOOK AND PERSPECTIVES}

Practical model identifiability of the constitutive functions, Eq. 4 and Eq. 6, describing hindered and compression settling velocity is important because, it can, for the first time, allow for the estimation of reliable, unique, posterior parameter values using sensor data. Bürger et al. (2011) propose a consistent modelling methodology (CMM) for SST that requires the use of consistent and reliable numerical method (solver) to satisfy the entropy condition - an admissibility criterion, ensuring physically relevant (stable) discontinuities appear in the numerical approximate solution. Practical identifiability as a criterion, extending the CMM, can alleviate ill-conditioned and ill-posed calibration problems, thereby reducing uncertainties, propagating to the simulation results. Compared to former constitutive assumptions (e.g., Takács et al., 1991; Torfs et al., 2017), the first study assessing practical identifiability, i.e., Ramin et al. (2014b), indicate partial compliance with 
identifiability criteria, and suggest further research on methods to infer experimental data and on mathematical functions. These recommendations formed the main aims of the present study. Regarding the column sensor setup presented here, the side TSS sensor indicate considerable shortcomings at comparably high initial solid concentration. This inefficiency, once overcome, can potentially decrease the uncertainties in compression settling model calibration by means of global optimisation and simple regression analysis. The constitutive functions for hindered-compression settling combined with the probe settling column setup proposed here can, for the first time, allow practitioners to develop reliable and updatable model-based decision support and process control structures to mitigate the impacts of hydraulic shocks on WRRFs. An example for such a decision support system includes aeration tank settling (Thornberg et al., 1998; Gernaey et al., 2004) - an effective means reducing the by-passed untreated sewage under wet-weather flow conditions.

\section{CONCLUSIONS}

The concluding remarks drawn in the study include:

- A pseudo two-parameter and a three-parameter exponential term were identified to describe hindered settling velocity and the effective compressive solids stress gradient, respectively. The ratio of $v_{0} / r_{H}$ was estimated with $v_{0}$ set as constant in the hindered settling function. Solids concentration is normalised using the $X_{\text {Infi }}$ parameter easily obtainable in regression analysis. The three parameters required to estimate using the global optimisation method are $v_{0} / r_{H}, v_{C}$ and $r_{C}-$ all practically identifiable using the data obtained using the innovative multi-probe column sensor setup.

- It is demonstrated that uncertainties, propagating from Bayesian prior settings to posterior parameter estimates can cause significant bias; and that the three-level parameter estimation 
method is effective in reducing this uncertainty propagation, and thus resulting in the uniqueness of posterior parameter estimate solutions by employing the sequential uniformGaussian Bayesian priors method;

- The novel constitutive functions for hindered-compression settling developed are validated using independent batch column sensor data obtained with well-settling and filamentous bulking solids. Additionally, model validation was carried out using independent full-scale measurement and CFD simulation results.

- It is demonstrated that negligible uncertainties are introduced into CFD simulations by the 1-D parameter estimation approach using the column sensor data. Additionally, the multiprobe settling sensor setup developed can be used to quantify the $\tau$-gradient, and future research should assess the benefits of using $\tau$-gradient sensor data for settling model calibration.

\section{ACKNOWLEDGEMENTS}

The co-authors wish to express their gratitude to University of Bath and the Technical University of Denmark (DTU) for supporting this research with internal funding. All co-authors express their deep appreciation and gratitude to the Reviewers of the manuscript, in particular, to Reviewer 1; their comments and suggestions greatly improved the content of the manuscript. J. Climent and S. Chiva gratefully acknowledge the support provided by Entitat de Sanejament d'Aigües de la Comunitat Valenciana (EPSAR). B. Valverde-Pérez and B.G. Plósz acknowledge the financial support obtained from the WISE project (Water Innovation SmE) funded by European Regional Development Fund (RFH-15-011) and the Capital Region Denmark (15006962). B.G. Plósz wishes to thank Prof Peter Steen Mikkelsen at DTU for his friendship, support and for the exciting 
discussions on climate change mitigation in the Storm- and Wastewater Informatics (SWI) project that inspired some of our ideas in the present research.

\section{REFERENCES}

Bernardo, J.M., 2000. Bayesian theory. Chichester: Wiley.

Bozdogan, H., 1987. Model selection and Akaike information criterion AIC - the general-theory and its analytical extensions. Psychometrika 52,345-370.

Bürger, R., Diehl, S., Farås, S., Nopens, I., Torfs, E., 2013. A consistent modelling methodology for secondary settling tanks: a reliable numerical method. Water Science and Technology 68, 192-208.

Bürger, R., Diehl, S., Nopens, I., 2011. A consistent modelling methodology for secondary settling tanks in wastewater treatment. Water Res. 45, 2247-2260.

Daigger, G.T., 1995. Development of refined clarifier operating diagrams using an updated settling characteristics database, Water Environ. Res. 67, 95-100.

De Clercq, J., Nopens, I., Defrancq, J., Vanrolleghem, P.A., 2008. Extending and calibrating a mechanistic hindered and compression settling model for activated sludge using in-depth batch experiments. Water Research 42, 781791.

De Clercq, J., 2006. Batch and continuous settling of activated sludge: in-depth monitoring and 1-D compression modelling. Ph.D. Thesis, University of Gent, Belgium.

De Clercq, J., Jacobs, J., Kinnear, D.J., Nopens, I., Dierckx, R.A., Defrancq, J., Vanrolleghem, P.A., 2005. Detailed spatio-temporal solids concentration profiling during batch settling of activated sludge using a radiotracer. Water Research 39, 2125-2135.

Derlon, N., Thürlimann, C., Dürrenmatt, D., Villez, K. 2017. Batch settling curve registration via image data modelling. Water Research 114, 327-337.

Diplas, P., Papanicolaou, A.N., 1997. Batch analysis of slurries in zone settling regime. J. Environ. Eng. 123, 659-667. Diehl, S., 2015. Numerical identification of constitutive functions in scalar nonlinear convection - diffusion equations with application to batch sedimentation. Applied Numerical Mathematics 95, 154-172.

Ekama, G.A., Barnard, J.L., Günthert, F.W., Krebs, P., McConcordale, J.A., Parker, D.S., Wahlberg, E.J., 1997. 
Secondary settling tank: theory, modelling, design and operation. Scientific and Technical Report No. 6. IAWQ, London.

Gernaey, K.V., Nielsen, M.K., Thornberg, D., Hook, B., Munk-Nielsen, T., Ingildsen, P., Jorgensen, S.B., 2004. Conservation principles suspended solids distribution modelling to support ATS introduction on a recirculating WWTP. Water Science and Technology 50, 179-188.

Guyonvarch, E., Ramin, E., Kulahci, M., Plósz, B.G. 2015. iCFD: Interpreted computational fluid dynamics Degeneration of CFD to one-dimensional advection-dispersion models using statistical experimental design The secondary clarifier. Water Research 83, 396-411.

Jeppsson, U., Alex, J., Batstone, D.J., Benedetti, L., Comas, J., Copp, J.B., Corominas, L., Flores-Alsina, X., Gernaey, K.V., Nopens, I., Pons, M.N., Rodriguez-Roda, I., Rosen, C., Steyer, J.P., Vanrolleghem, P.A., Volcke, E. I. P., Vrecko, D., 2013. Benchmark simulation models, quo vadis? Water Science and Technology 68, 1, 1-15.

Kass, R.E., Raftery, A.E., 1995. Bayes Factors. Journal of the American Statistical Association 90, 773-795.

Kinnear, D.J., 2002. Biological solids sedimentation: a model incorporating fundamental settling parameters. Ph.D. Thesis, Department of Civil and Environmental Engineering, University of Utah.

Lawlor, D.A., Tilling, K., Smith, G.D., 2016. Triangulation in aetiological epidemiology. Int. J. Epidemiology, 45, 6, 1866-1886.

Li, B., Stenstrom, M.K., 2016. Practical identifiability and uncertainty analysis of the one-dimensional hinderedcompression continuous settling model. Water Research 90, 235-246.

Nelder, J.A., Mead, R., 1965. A simplex method for function minimization. Computational Journal. 7, 308-313.

Plósz, B.G., Weiss, M., Printemps, C., Essemiani, K., Meinhold, J. (2007) One-dimensional modelling of the secondary clarifier - factors affecting simulation in the clarification zone and the assessment of the thickening flow dependence. Water Research 41, 3359-3371.

Plósz, B.G., Liltved, H., Ratnaweera, H., 2009. Climate change impacts on activated sludge wastewater treatment: A case study from Norway. Water Science and Technology 60, 2, 533-541.

Raiffa, H. and Schlaifer, R., 1961. Applied statistical decision theory. Clinton Press, Inc., Boston, USA.

Ramin, E., Sin, G., Mikkelsen, P.S., and Plósz, B.G., 2014a. Significance of settling model structures and parameter subsets in modelling WRRFs under wet-weather flow and filamentous bulking conditions. Water Research 63, 209-221.

Ramin, E., Wágner, D.S., Yde, L., Binning, P.J., Rasmussen, M.R., Mikkelsen, P.S., Plósz, B.G. 2014b. A new settling 
velocity model to describe secondary sedimentation. Water Research 66, 447-458.

Ramin, P., Valverde-Pérez, B., Polesel, F., Locatelli, L., Plósz, B.G. 2017. A systematic model identification method for chemical and biochemical transformation pathways - the case of heroin biomarkers in wastewater. Scientific Report, 7:9390, 1-11.

Saltelli, A., Ratto, M., Andres, T., Campolongo, F., 2008. Global sensitivity analysis: the primer. John Wiley \& Sons, West Sussex, England.

Sin, G., Gernaey, K.V., Neumann, M.B., van Loosdrecht, M.C.M., Gujer, W., 2011. Global sensitivity analysis in wastewater treatment plant model applications: prioritizing sources of uncertainty. Water Research 45, 639-651.

Takács, I., Patry, G.G., Nolasco, D., 1991. A dynamic model of the clarification-thickening process. Water Research 25, $1263-1271$.

Thornberg, D.E., Nielsen, M., Eriksson, J., 1998. Upgrading of Boras wastewater treatment plant based on intelligent process and operation control. Water Science and Technology 37, 57-63.

Torfs, E., Balemans, S., Locatelli, F., Diehl, S., Bürger, R., Laurent, J., Francois, P., Nopens, I., 2017. On constitutive functions for hindered settling velocity in 1-D settler models: selection of appropriate model structure. Water Research 110, 38-47.

Valverde Pérez, B., Penkarski-Rodon, E., Zhang, X., Wágner, D.S., Haecky, P., Blackburn, N.D., Plósz, B.G. 2017. quantification of settling properties with in-sensor-experiments in an automated settlometer. Water Science and Technology 33, 37-51.

Vesilind, P.A., 1968. Design of prototype thickeners from batch settling tests. Water Sewage Works 115, 302-307.

Wágner, D.S., Valverde-Pérez, B., Sæbø, M., Bregua de la Sotilla, M., Van Wagenen, J., Smets, B.F., Plósz, B.G., 2016. Towards a consensus-based biokinetic model for green microalgae-the ASM-A. Water Research 103, 485-499.

Weiss, M., Plósz, B.G., Essemiani, K., Meinhold, J. 2007. Suction-Lift Sludge Removal and Non-Newtonian Flow Behaviour in Circular Secondary Clarifiers: Numerical Modelling and Measurements. Chemical Engineering 

Journal 132, 241-255.

614 Xu, G., Yin, F., Xu, Y., Yu, H.Q., 2017. A force-based mechanistic model for describing activated sludge settling process. 615 Water Research 127, 118-126.

616 
FIGURES

Hindered and compression solid settling functions - sensor data collection, practical model identification and validation

620

621 

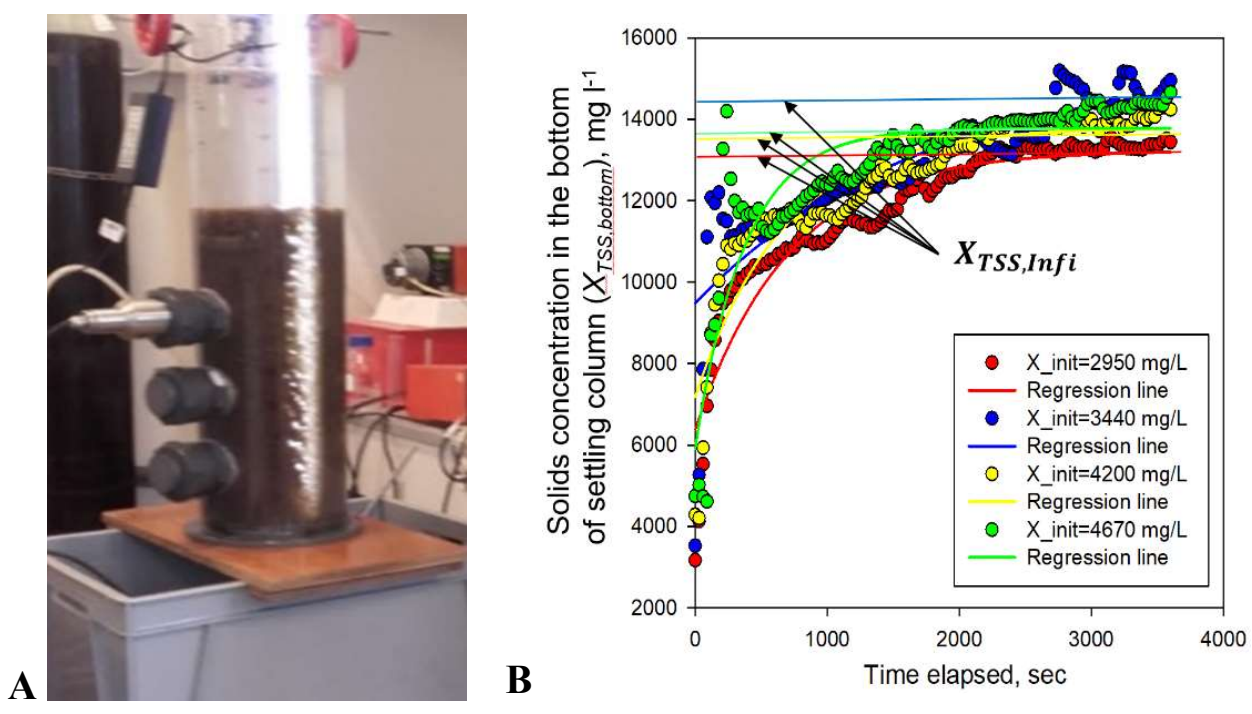

627 Figure 1. The multi-probe column sensor prototype - (A) equipped with two SOLITAX TSS sensors installed in the bottom (not visible in the photo) and the sidewall of the settling column; and (B) TSS values measured at the bottom of the settling column $\left(X_{T S S, B o t t o m}\right)$ versus experimental time and regression lines (Eq. 1) used to estimate $X_{\text {TSS, Infi }}$ values (Fig. 3d) - example shown here include the settling experiments with Fredericia WRRF sludge. 

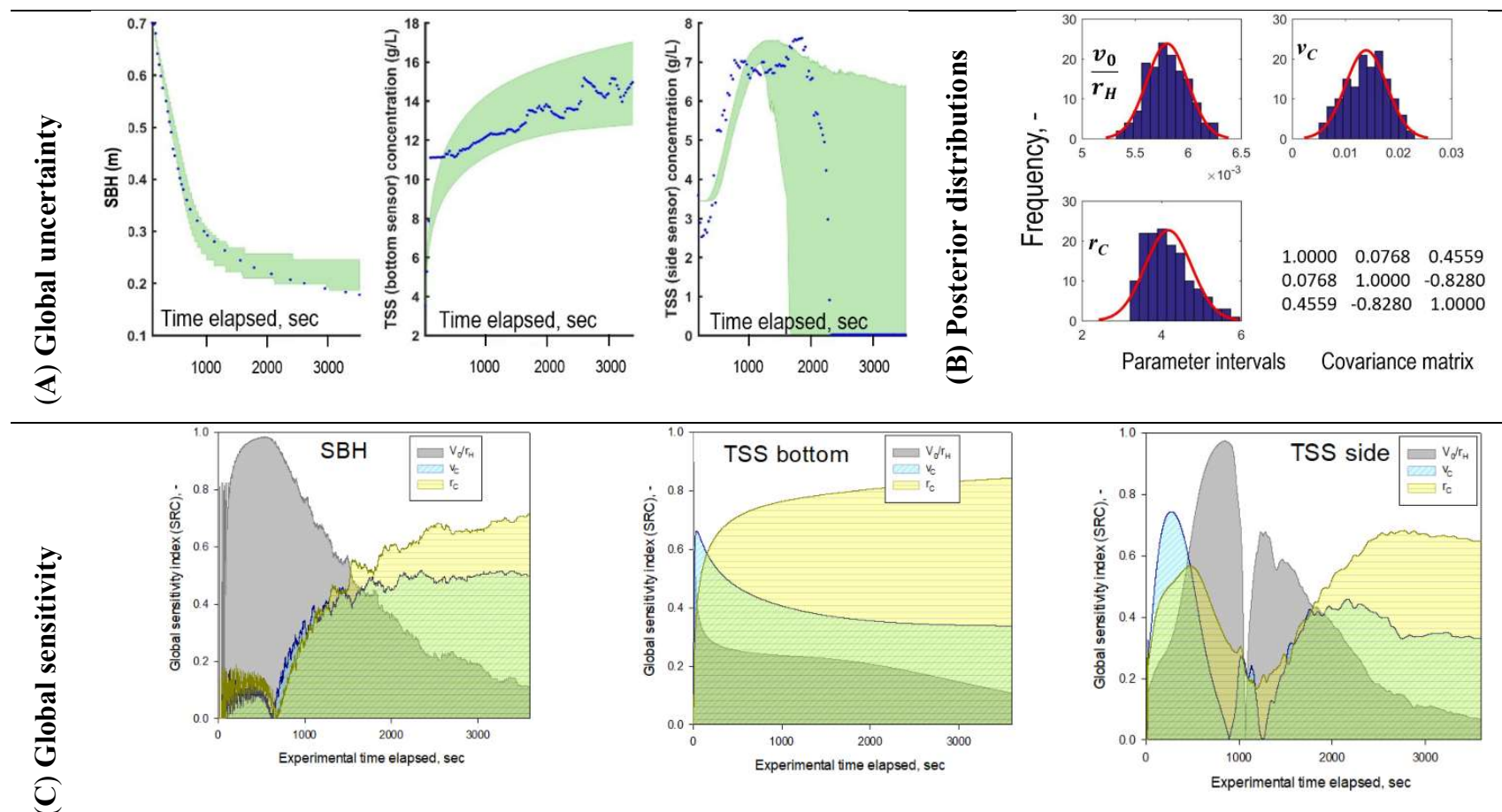

633

634

635

636

637

638

639

640

641

642

643

Figure 2. Practical model identification using data obtained with well-settling solids - measured and simulated data for activated sludge collected in Fredericia WRRF using the new hinderedcompression settling velocity functions; Initial solid concentration: $3.44 \mathrm{~g} \mathrm{~L}^{-1}$; Proposed/a priori probability ranges: $v_{0} / r_{H}=[0.00520 .0063] ; v_{C}=[0.0050 .025] ; r_{C}=[2.55 .5] ;$ (A) Global uncertainty plots with $95 \%$ confidence intervals, (B) posterior parameter density distributions with parameter intervals showing the a priori probability ranges, (C) values of dynamic sensitivity (SRC) and (D) coefficient of determination $\left(\mathrm{R}^{2}\right)$ computed for SBH, $X_{T S S \text {, bottom }}$ and $X_{T S S \text {, side }}$ concentration statevariables. Further results obtained with different dilutions of the activated sludge collected in Fredericia WRRF are shown in Fig. S2-S5. 
A

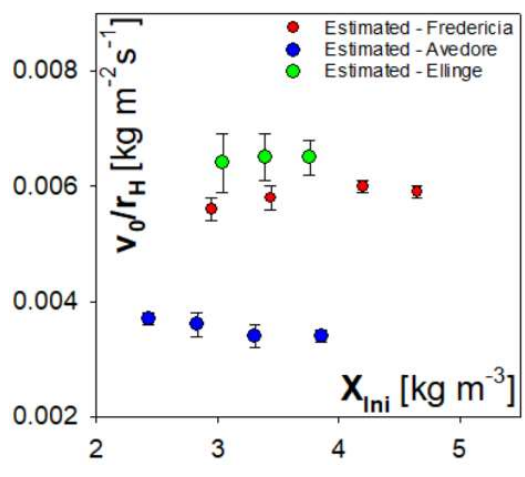

C

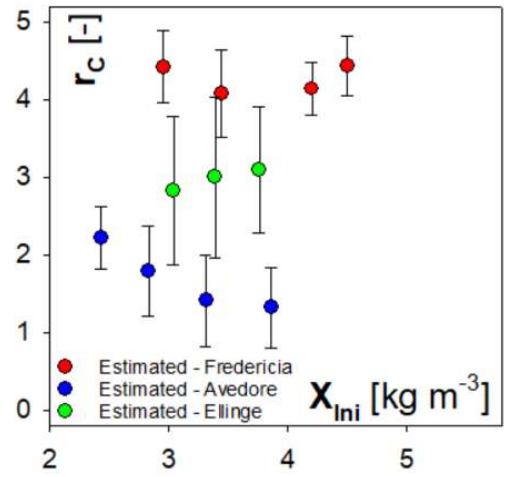

B

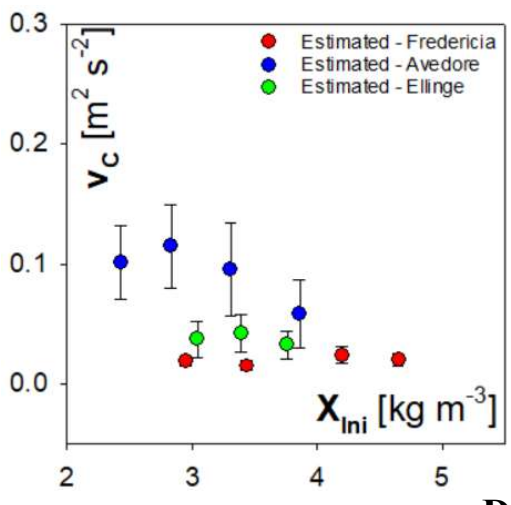

D

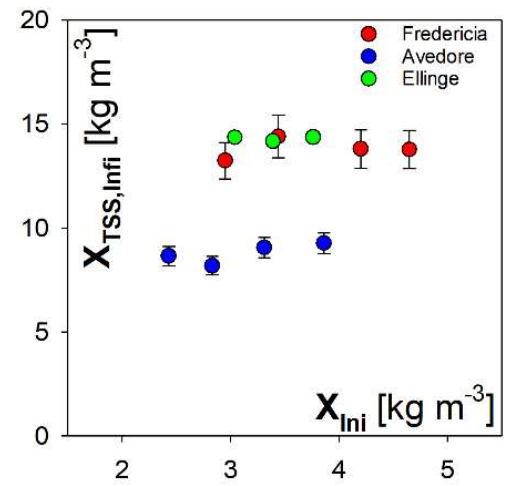

644 Figure 3. Posterior mean $v_{0} / r_{H}(\mathrm{~A}), v_{C}(\mathrm{~B}), r_{C}(\mathrm{C})$ parameter values with $95 \%$ confidence interval 645 denoted with error bars obtained with well-settling solids (Fredericia and Ellinge WRRFs) and solids 646 with filamentous bulking (Avedøre WRRFs); and (D) $X_{T S S, I n f i}$ values obtained using regression 647 analysis for Fredericia, Ellinge and Avedøre WRRFs. 

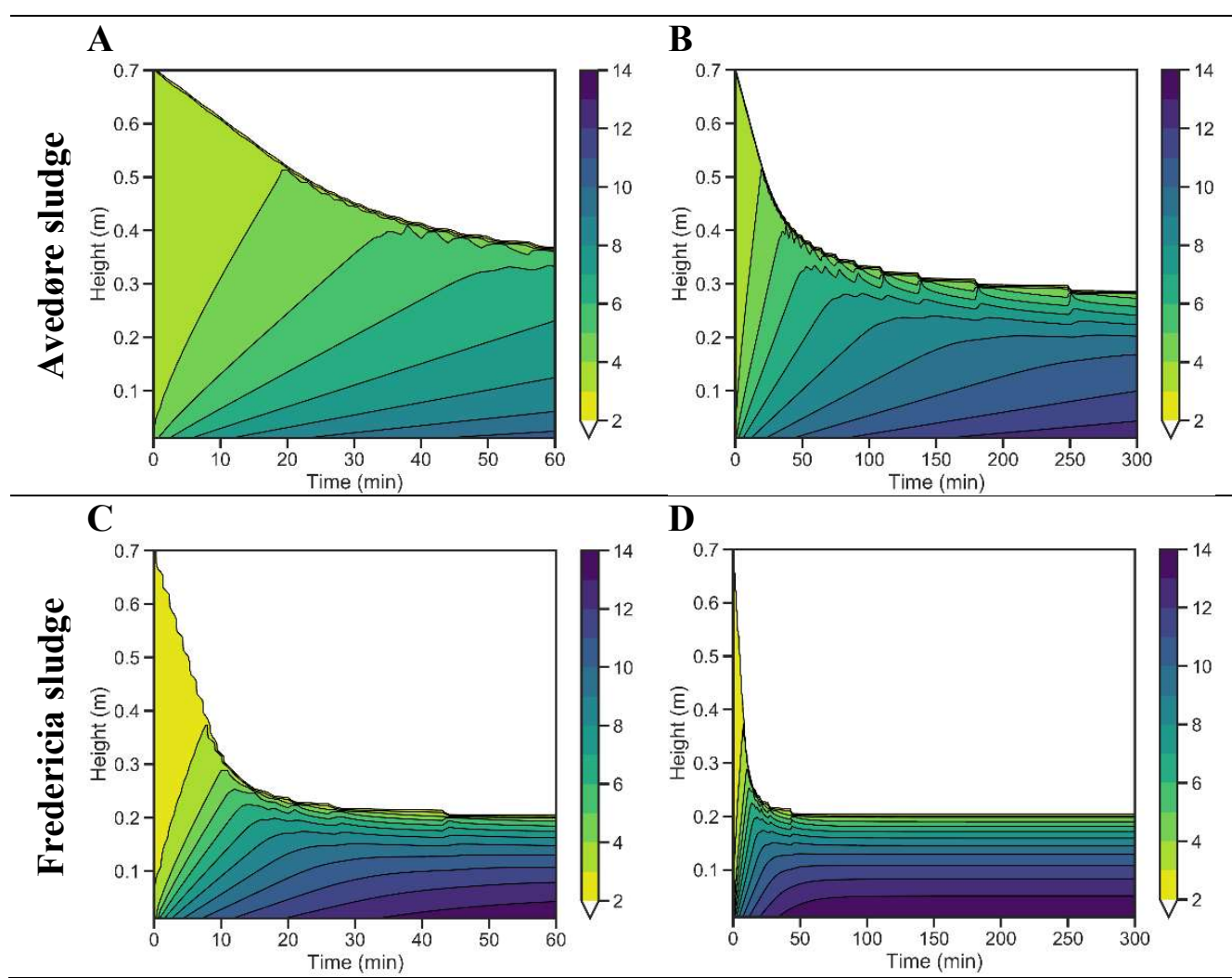

649 Figure 4. Iso-concentration contour plots ( $X$ shown in colour fill legend) predicted in the batch 650 settling tests of (A-B) Avedøre WRRF - filamentous bulking sludge $\left(X_{\text {Ini }}=3.9 \mathrm{~g} \mathrm{l}^{-1}\right)$ with experimental 651 times of 60 and 300 minutes; (C-D) Fredericia WRRF - well-settling sludge $\left(X_{\text {Inl }}=2.95 \mathrm{~g} \mathrm{l}^{-1}\right)$ with 652 experimental times of 60 and 300 minutes.

653 


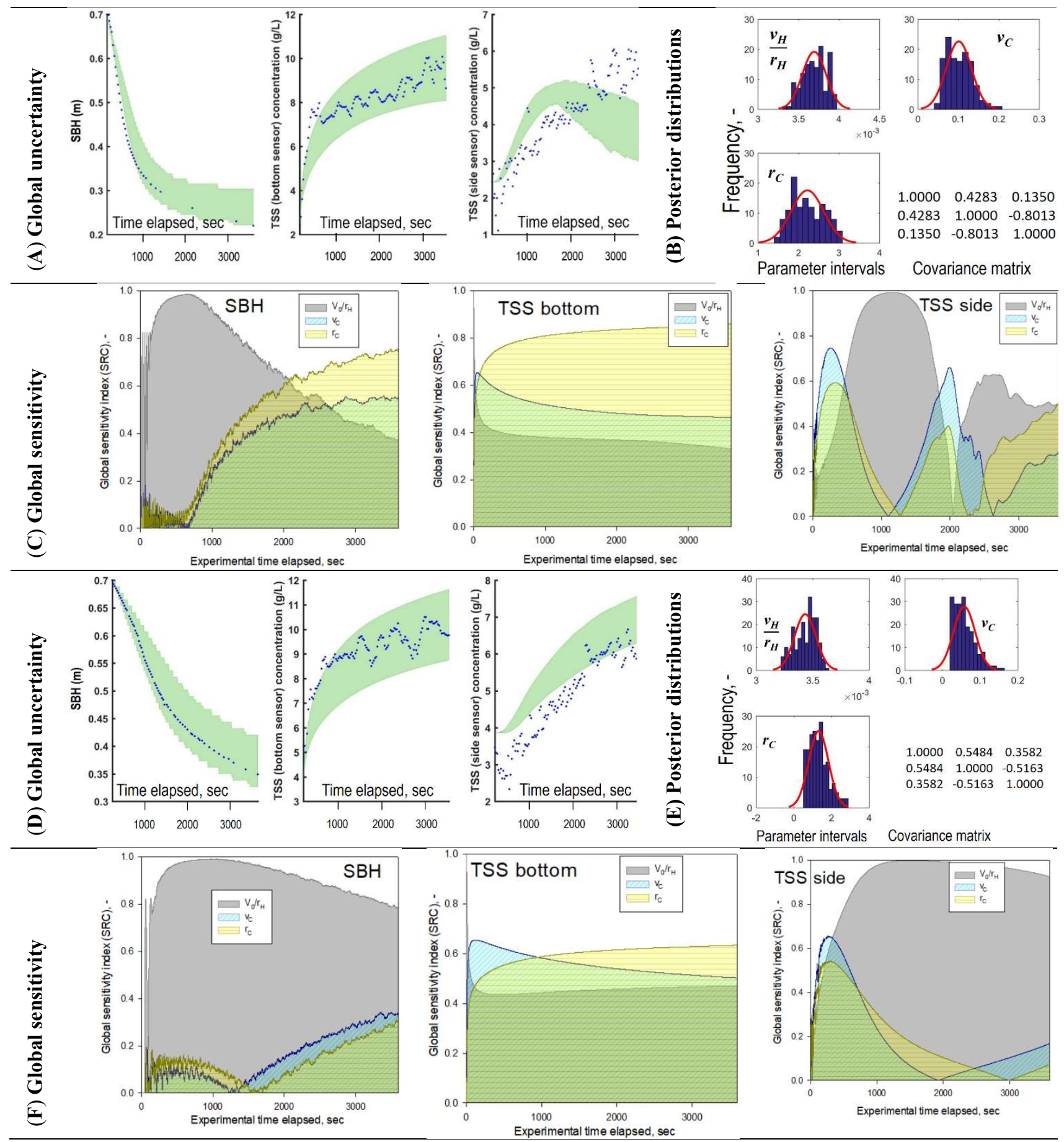

Figure 5. Model validation using data obtained with filamentous bulking solids - measured and simulated data for activated sludge collected in Avedøre WRRF using the new hindered-compression process model; Initial solid concentration: $2.4 \mathrm{~g} \mathrm{~L}^{-1}$ (A, B, C); Proposed probability ranges: $v_{0} / r_{H}=\left[\begin{array}{ll}0.003 & 0.004\end{array}\right] ; v_{C}=\left[\begin{array}{ll}0.02 & 0.2\end{array}\right] ; r_{C}=\left[\begin{array}{ll}0.5 & 3\end{array}\right]$; Initial solid concentration: $3.9 \mathrm{~g} \mathrm{~L}^{-1}(\mathrm{D}, \mathrm{E}, \mathrm{F})$; Proposed probability ranges: $v_{0} / r_{H}=[0.0030 .004] ; v_{C}=[0.010 .2] ; r_{C}=[0.13]$; Global uncertainty plots with $95 \%$ confidence intervals, posterior parameter density distributions; SRC and $\mathrm{R}^{2}$ values shown in Fig. S9. 
663

$\mathbf{a}$

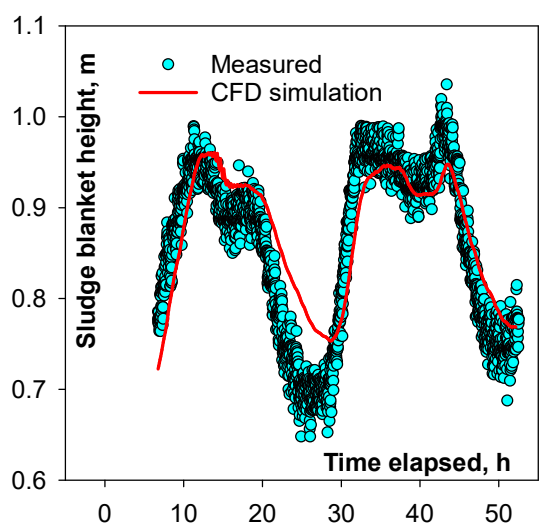

b

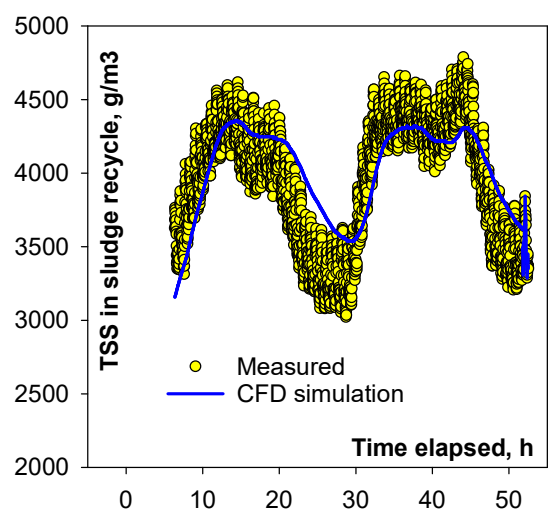

C

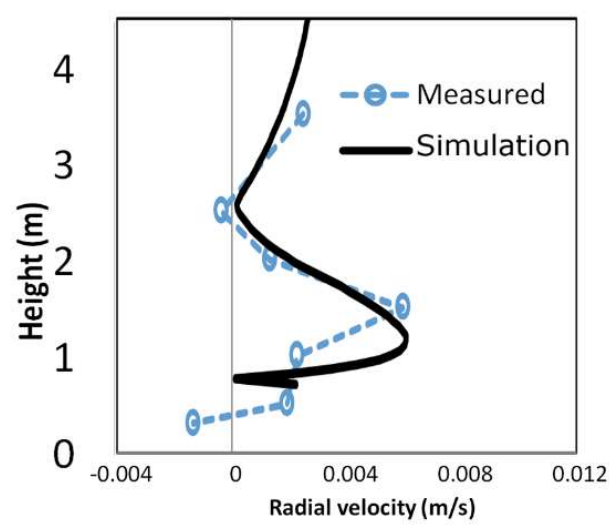

664 Figure 6. Measured and simulated (a) sludge blanket height, SBH, (b) TSSRAS concentration, and (c) 665 vertical radial velocity profile (more information on the velocity metering shown in SI) in the full666 scale SST in OBVA WRRF, Vila-Real, Spain.

667

668 
669
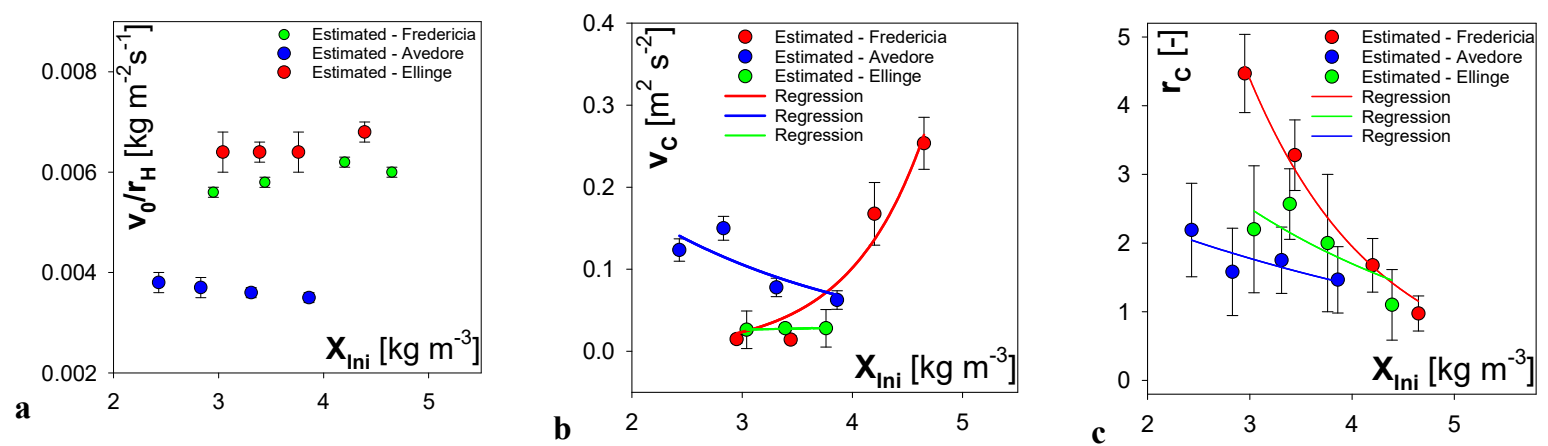

670 Figure 7. Posterior mean settling velocity parameter values with confidence interval (denoted with error bars) obtained for Fredericia, Ellinge and Avedøre datasets in Level 1 (Table 1) using LHSS with uniform a priori/proposed parameter probability density distribution; Parameter estimates obtained in Level 2 (Table 1) using Gaussian a priori (conjugate) parameter probability distribution is shown in Fig. 3.

675

676 
A

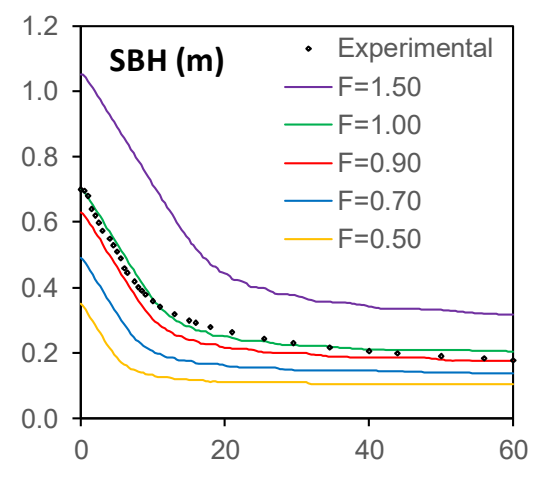

D

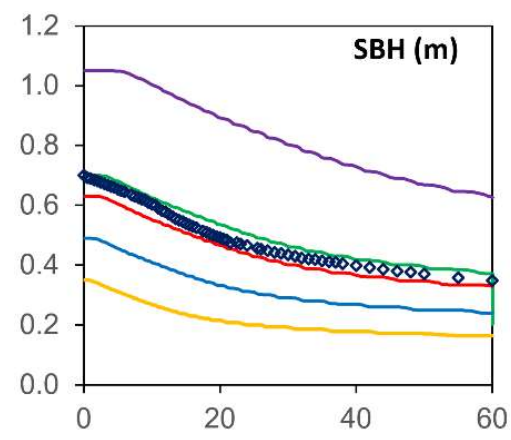

B

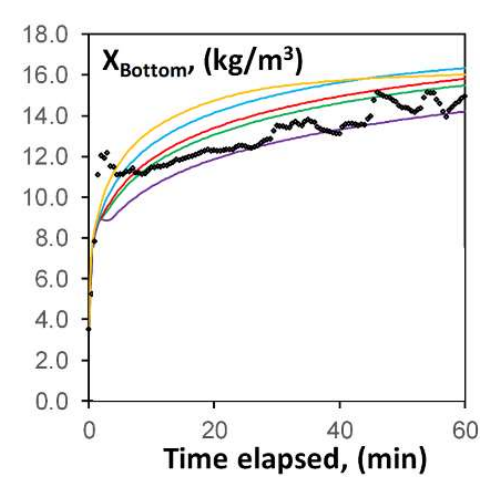

E

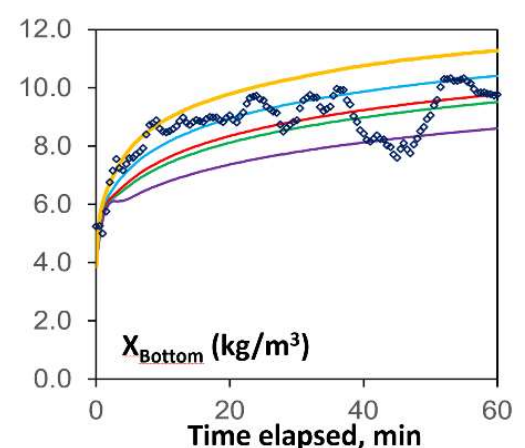

C

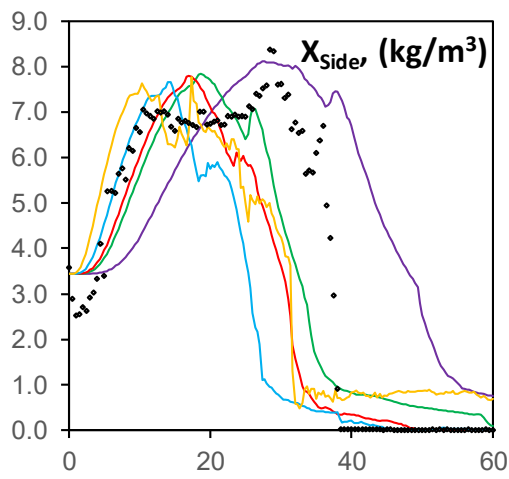

F

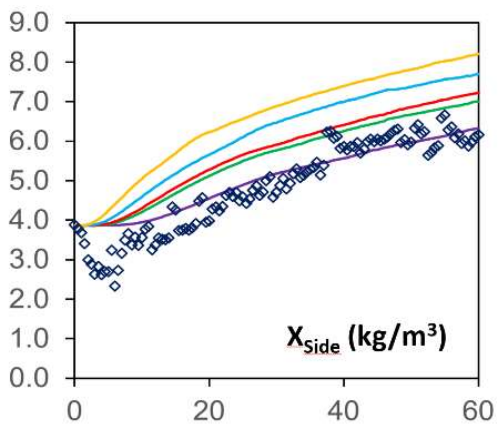

682

Figure 8. Measured and CFD simulation results obtained for the settling column sensors, sized according to different design similarity factors $(F)$ and compared to the real setup ( $F=1$; Fig. 1a), in terms of $S B H, X_{\text {Bottom }}$ and $X_{\text {Side }}$ using solver calibrated according to parameter values obtained with (A, B , C) Fredericia WRRF sludge at $\mathrm{X}_{\mathrm{ini}}=3.44 \mathrm{~g} / \mathrm{l}$ (Fig. 2); and (D, E, F) Avedøre WRRF sludge at $\mathrm{X}_{\text {ini }}=3.9 \mathrm{~g} / 1$ (Fig. S12). 

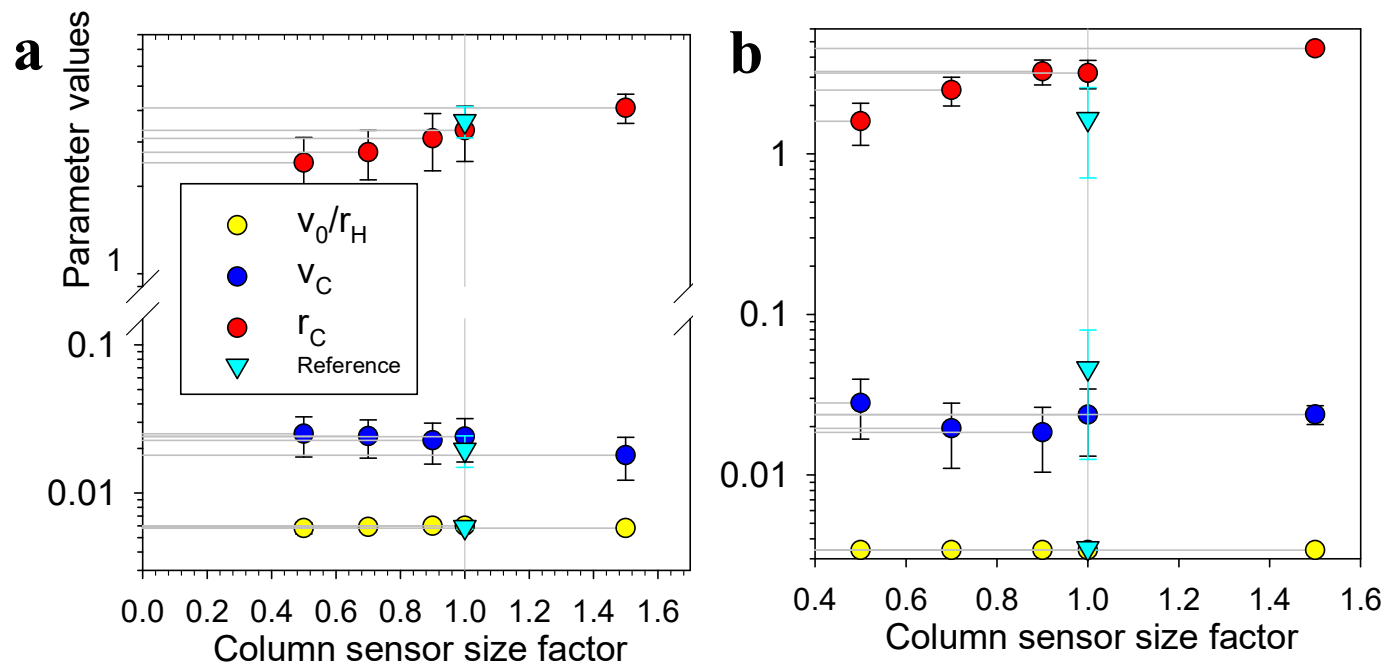

685 Figure 9. Settling model parameters estimated with the different column designs (see Fig. 5) using CFD simulation output data obtained using calibration parameter sets for (A) well-settling sludge from Fredericia WRRF and (B) sludge with filamentous bulking collected in Avedøre WRRF. Reference parameter values shown were obtained using measured settling data (Fig. 2 and Fig. S12). 
691
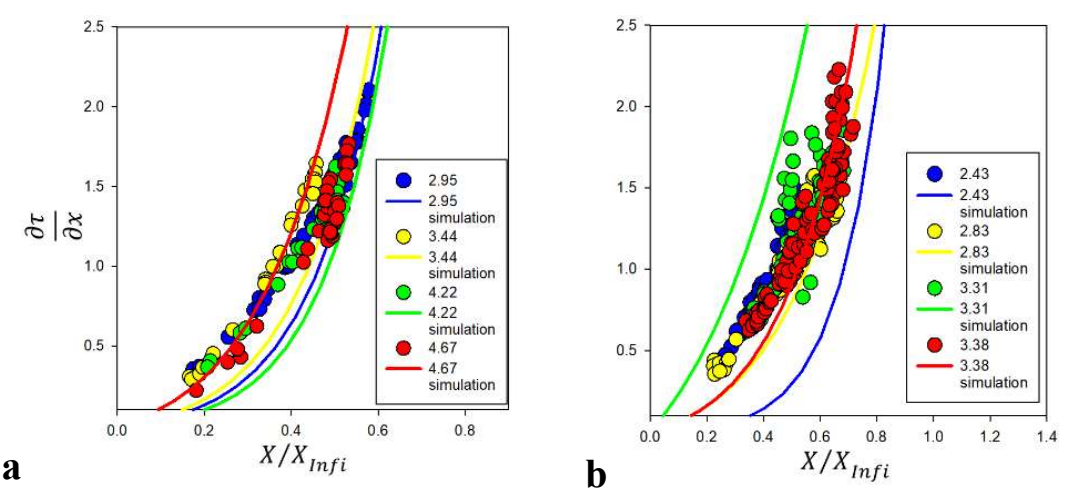

692 Figure 10. Calculated based on measured data (Eq. 4) and simulated compressive solid stress

693 derivative values plotted as a function of the $X_{\text {Side }} / X_{\text {Inf } i}$ values using (a) well-settling sludge from

694 Fredericia WRRF and (b) sludge with filamentous bulking collected in Avedøre WRRF. 


\section{TABLES}

Hindered and compression solid settling functions - sensor data collection, practical model identification and validation

699

700

701

Benedek G. Plósz ${ }^{1,3,}$, Javier Climent ${ }^{2}$, Christopher T. Griffin ${ }^{1}$, Sergio Chiva ${ }^{2}$, Rani Mukherjee ${ }^{1}$, Elena

702

Penkarski-Rodon ${ }^{3}$, Matthew Clarke ${ }^{1}$, and Borja Valverde-Pérez ${ }^{3}$

703

704

705 
706 Table 1. The two-level practical model identification and parameter estimation method

\begin{tabular}{|c|c|}
\hline & thm - Level 1 : Assessing practical model identifiability using LHSS (discrimination of functions) \\
\hline 1. & $\begin{array}{l}\text { Definition of a priori parameter ranges, } \mathrm{p}(\boldsymbol{\theta}) \text {, where } \boldsymbol{\theta}=\left\{\theta_{1}, \ldots, \theta_{\mathrm{j}}\right\} \text { denotes a j-vector of model } \\
\text { parameters using uniform probability distribution; }\end{array}$ \\
\hline 2. & Latin hypercube sampling, LHS from $\mathrm{p}(\boldsymbol{\theta})$ \\
\hline 3. & 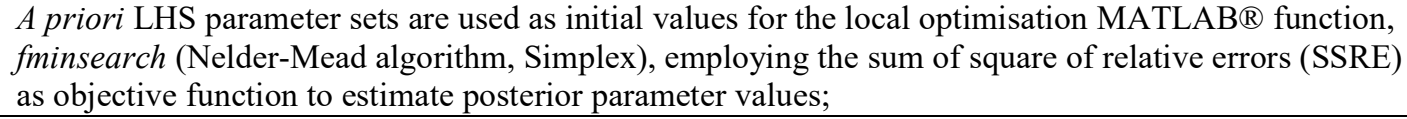 \\
\hline 4. & $\begin{array}{l}\text { Visualisation of posterior parameter probability density distribution, } \mathrm{p}(\boldsymbol{\theta} \mid \mathrm{x})-\text { with } \mathrm{x}=\left\{\mathrm{x}_{1}, \ldots, \mathrm{x}_{\mathrm{n}}\right\} \text { an } \\
n \text {-vector of measurements - using histograms, excluding any parameter values with SSRE values } \\
\text { higher than a selected threshold }(10 \% \text { of the minimum SSRE) - considered as local minima; }\end{array}$ \\
\hline 5. & Average parameter values, standard deviations and correlation matrix are computed; \\
\hline 6. & $\begin{array}{l}\text { Practical model identifiability } \\
\text { a. }(\mathrm{p}(\boldsymbol{\theta} \mid \mathrm{x})) \text { : histograms are interpreted in terms of (i) probability distribution: Gaussian distribution } \\
\text { indicate parameter identifiability vs. uniform distribution indicates non-identifiability; (ii) } \\
\text { narrow histograms indicate parameter identifiability; }\end{array}$ \\
\hline & $\begin{array}{l}\text { b. Correlation matrix, } \operatorname{cov}(\widehat{\theta}) \text { : correlation of parameters are assessed by considering a } \\
\text { collinearity threshold }(\mathrm{CT}) \text { for identifiability to be } 0.7 \text {; If for any pairs of parameters, } \theta_{j} \theta_{j} \text {, }\end{array}$ \\
\hline & $\mathrm{CT}>0.7$, then these parameters are considered identifiable; If $J^{2}=$ \\
\hline & $\underline{\frac{1}{n} \sum_{i=1}^{n}\left(y_{\text {exp }, p, i}-y_{\text {sim }, i}\left(t_{i}, \widehat{\theta}_{j}+\sigma_{j}\right)\right)^{2}}=\frac{\sum_{i=1}^{n}\left(y_{\text {exp }, p, i}-y_{s i m, i}\left(t_{i}, \widehat{\theta}_{j}+\sigma_{j}\right)\right)^{2}}{1} \sim$ \\
\hline & $\overline{\frac{1}{n} \sum_{i=1}^{n}\left(y_{\text {exp }, p, i}-y_{\text {sim }, i}\left(t_{i}, \widehat{\theta}_{j}-\sigma_{j}\right)\right)^{2}}=\overline{\sum_{i=1}^{n}\left(y_{\text {exp }, p, i}-y_{s i m, i}\left(t_{i}, \widehat{\theta}_{j}-\sigma_{j}\right)\right)^{2}} \sim 1$ \\
\hline & where, $J^{2}$ is the Janus coefficient, $y_{\text {exp }, p, i}$ is the $\mathrm{i}^{\text {th }}$ experimental data of the $\mathrm{p}^{\text {th }}$ variable, $y$, and \\
\hline & $y_{s i m, i}\left(t_{i}, \widehat{\theta}_{j}+\sigma_{j}\right)$ is the simulation model output at the $\mathrm{i}^{\text {th }}$ time point, $\widehat{\theta}_{j}$ is the mean optimal \\
\hline & $\begin{array}{l}\text { parameter value, } \sigma_{j} \text { is the corresponding standard deviation of } \theta_{j} \text {, and } n \text { is the number of } \\
\text { experimental data used; else the parameters are considered non-identifiable; }\end{array}$ \\
\hline 7. & Selection between candidate model structures. Calculate the Akaike Information Criterion (AIC) and \\
\hline & Bayesian Information Criterion (BIC) values for the practically identifiable models (Supporting \\
\hline & Information), and use AIC and BIC as selection criteria to compare alternative model structures. \\
\hline & ithm - Level 2 : Re-estimation of $\mathrm{p}(\boldsymbol{\theta} \mid \mathrm{x})$ by considering Gaussian conjugate priors \\
\hline 8. & Definition of a priori parameter ranges $\mathrm{p}(\boldsymbol{\theta})$ using normal, Gaussian probability distribution; \\
\hline & These steps follow Steps 2-5 in Level 1. \\
\hline & ithm - Level 3 : Assessing experimental design conducive to practical identifiability \\
\hline & e standardised regression coefficient (SRC) is calculated; experimental data with high SRC indi \\
\hline
\end{tabular}


710 Table 2. Akaike Information Criterion (AIC) and Bayesian Information Criterion (BIC) values

711 calculated using the objective functions (OF) calculated for $\hat{\theta}_{j} \pm \sigma_{j}$. Lower AIC/BIC values indicate

712 a superior set of functions. See also (Step 7@Level 1, Table 1).

\begin{tabular}{l|ccc}
\hline & New functions & Diehl-DeClercq functions & HTC functions \\
\hline $\mathbf{A I C}\left(\mathrm{OF}_{1}, \hat{\theta}_{j}+\sigma_{j}\right)$ & 10.7 & 16.4 & 18.4 \\
$\mathbf{A I C}\left(\mathrm{OF}_{1}, \hat{\theta}_{j}-\sigma_{j}\right)$ & 10.6 & 16.8 & 18.5 \\
$\mathbf{A I C}\left(\mathrm{OF}_{2}, \hat{\theta}_{j}+\sigma_{j}\right)$ & 12.5 & 17.8 & 19.9 \\
$\mathbf{A I C}\left(\mathrm{OF}_{2}, \hat{\theta}_{j}-\sigma_{j}\right)$ & 12.4 & 18.8 & 20.1 \\
\hline $\mathbf{B I C}\left(\mathrm{OF}_{1}, \hat{\theta}_{j}+\sigma_{j}\right)$ & 21.6 & 38.1 & 43.7 \\
$\mathbf{B I C}\left(\mathrm{OF}_{1}, \hat{\theta}_{j}-\sigma_{j}\right)$ & 21.5 & 38.5 & 43.8 \\
$\mathbf{B I C}\left(\mathrm{OF}_{2}, \hat{\theta}_{j}+\sigma_{j}\right)$ & 23.4 & 39.5 & 45.2 \\
$\mathbf{B I C}\left(\mathrm{OF}_{2}, \hat{\theta}_{j}-\sigma_{j}\right)$ & 23.2 & 40.5 & 45.4 \\
\hline
\end{tabular}

713

714

715

716 


\section{Hindered and compression solid settling functions - sensor data} collection, practical model identification and validation

Benedek G. Plósz ${ }^{1,3, *}$, Javier Climent², Christopher T. Griffin ${ }^{1}$, Sergio Chiva ${ }^{2}$, Rani Mukherjee ${ }^{1}$, Elena Castellón (Spain),(Email: jcliment@uji.es, schiva@uji.es) 


\section{Discrimination of the hindered - compression settling functions based on practical identifiability criteria}

With the exception of the the process model by Ramin et al. (2014), the hindered - compression settling functions tested in this study - other than that presented in the main body of text - can be described with the equation

$v_{s}=\left\{\begin{array}{cl}v_{H} & X \leq X_{T S S, C} \\ v_{H}\left(1-\frac{\rho_{S}}{\left(\rho_{S}-\rho_{f}\right) g X} \frac{\partial \sigma}{\partial X} \frac{\partial X}{\partial z}\right) & X>X_{T S S, C}\end{array}\right\}$

743

744

745

746

747

748

749

750

751

752

753

754

755

756

757

758

759

760

761

762

763

764

where $v_{H}$ is the hindered settling velocity; $X$ is the sludge concentration; $X_{T C}$ is the threshold concentration for the onset of compression settling, $\partial \sigma / \partial X$ is the effective solid stress gradient, $z$ is the vertical direction variable, and $g$ is the gravity acceleration constant. $D_{i}$ denotes generic model parameters with a subscript representing the number of parameters in each constitutive function. We note that the process model by Ramin et al. (2014) also includes a transient settling velocity function; and for the formulation of the process model, the reader is referred to the original publication.

Briefly, the HTC model and the Diehl hindered settling function were tested, and results are presented in this chapter. In summary, the practical identifiability of the HTC model was assessed for all three sets of experiments, and related shortcomings - further detailed below - with the functions formed the main motivation for the present study. The practical identifiability of the compression function by De Clercq et al. (2008) was assessed by Ramin et al. (2014b), and shortcomings with the function - reported in the same paper - then formed the main motivation for developing the compression settling model presented as the HTC model by Ramin et al. (2014b). Noteworthy is that these shortcomings of the De Clercq's compression settling function were also shown by Li and Stenstrom (2016).

For discrimination of hindered - compression settling functions, the Diehl-DeClercq and the HTC models, both including hindered and compression settling functions were assessed in-depth using practical identifiability criteria. 
Table SI-i1. Alternative constitutive functions for hindered-transient-compression settling assessed in this study.

\begin{tabular}{|c|c|}
\hline Name of function, references & Constitutive functions \\
\hline \multicolumn{2}{|l|}{ Hindered settling $\left(\mathrm{v}_{\mathrm{H}}\right)$} \\
\hline $\begin{array}{l}\text { Diehl (2008); Torfs et al. (2017) } \\
\text { Function in the Diehl-DeClercq model }\end{array}$ & $\mathrm{v}_{0} /\left(1+(\mathrm{X}(\mathrm{i}) / \bar{X})^{\wedge} \mathrm{q}\right)$ \\
\hline $\begin{array}{c}\text { Vesilind (1968) } \\
\text { Function in the HTC model }\end{array}$ & $\mathrm{v}_{0} * \exp \left(-\mathrm{r}_{\mathrm{H}} * \mathrm{X}(\mathrm{i})\right)$ \\
\hline \multicolumn{2}{|l|}{ Transient settling } \\
\hline $\begin{array}{l}\text { Ramin et al. (2014) } \\
\text { Function in the HTC model }\end{array}$ & $\mathrm{v}_{\mathrm{t}}^{*} \exp \left(-\mathrm{r}_{\mathrm{t}}^{*} \mathrm{X}(\mathrm{i})\right)$ \\
\hline \multicolumn{2}{|l|}{ Compressive/effective solid stress } \\
\hline $\begin{array}{l}\text { Ramin et al. (2014) } \\
\text { Function in the HTC model }\end{array}$ & $\begin{array}{c}\left(\left(\mathrm{X}(\mathrm{i})-\mathrm{X}_{\mathrm{C}, \text { limit }}\right) / \mathrm{C}_{1}\right)^{\wedge} \mathrm{C}_{2} \\
\text { where } \mathrm{C}_{2} \text { is found dependent (exponential } \\
\text { function) on the initial solids concentration. } \\
\text { The exponential function includes two } \\
\text { regression parameters. }\end{array}$ \\
\hline $\begin{array}{l}\text { De Clercq et al. (2008) } \\
\text { Function in the Diehl-DeClercq model }\end{array}$ & $\begin{array}{l}\qquad \alpha^{*} \ln \left(\left(\mathrm{X}(\mathrm{i})-\mathrm{C}_{\mathrm{g}}+\beta\right) / \beta\right) \\
\text { where } \mathrm{D}_{2} \text { is found dependent (power function) } \\
\text { on the initial solids concentration. The power } \\
\text { function includes two regression parameters. }\end{array}$ \\
\hline
\end{tabular}

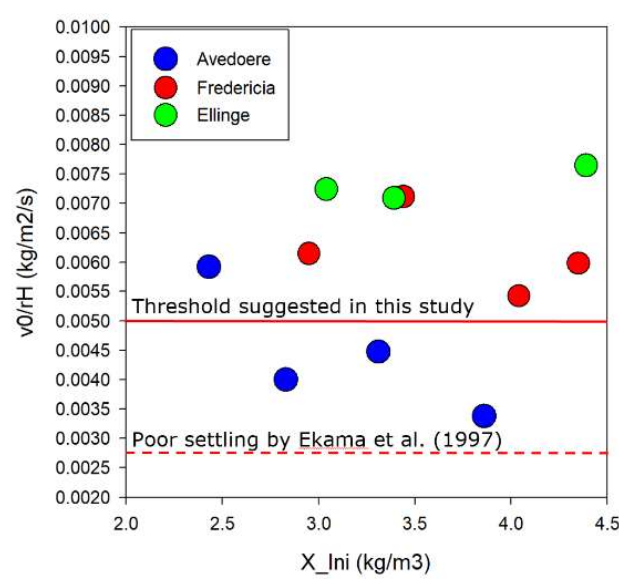

Figure. SI-i1 Examples drawn from the process model development study using the HTC model. (top chart) Posterior mean $\mathrm{v}_{0} / \mathrm{r}_{\mathrm{H}}$ values estimated with the HTC model (Ramin et al., 2014), showing high variability in parameter estimates as a function of initial sludge concentration. For the Avedoere WRRF, $\mathrm{v}_{0} / \mathrm{r}_{\mathrm{H}}$ values show both reasonably good and poor settling for the same sludge sample, which is one of the main drawbacks (other than those described in Ramin et al., 2014) that prompted the present study to be undertaken. 


\section{Calculation of the AIC and BIC values (Table 1)}

The two-level practical model identification and parameter estimation method is carried out according to Table 1. In Step 7@Level 1, the selection between candidate model structures is carried out Calculate the Akaike Information Criterion (AIC) and Bayesian Information Criterion (BIC) values, including the objective functions $\left(\mathrm{OF}_{\mathrm{f}}\right)$ of mean sum of the squared errors (SSE) calculated for $\hat{\theta}_{j} \pm \sigma_{j}$

$$
O F_{1}=\frac{S S E}{n}=\frac{\sum_{i=1}^{n}\left(y_{\text {exp }, p, i}-y_{\text {sim }, i}\left(t_{i}, \widehat{\theta}_{j} \pm \sigma_{j}\right)\right)^{2}}{n}
$$

and and the root mean squared errors (RMSE):

in the AIC as

$$
O F_{2}=R M S E=\sqrt{\frac{S S E}{n}}
$$

and use AIC as a selection criterion to compare model structures; alternatively, one can also use e.g., the BIC, given as

$$
B I C=2 \cdot \log (O F)+j \cdot \log (n)
$$

where, $y_{\text {exp, }, i}$ is the $\mathrm{i}^{\text {th }}$ experimental data of the $\mathrm{p}^{\text {th }}$ variable, $y$, and $y_{\text {sim }, i}\left(t_{i}, \widehat{\theta}_{j}+\sigma_{j}\right)$ is the simulation model output at the $\mathrm{i}^{\text {th }}$ time point, $\widehat{\theta}_{j}$ is the mean optimal parameter value, $\sigma_{j}$ is the corresponding standard deviation of $\theta_{j}$, and $n$ is the number of experimental data used. 


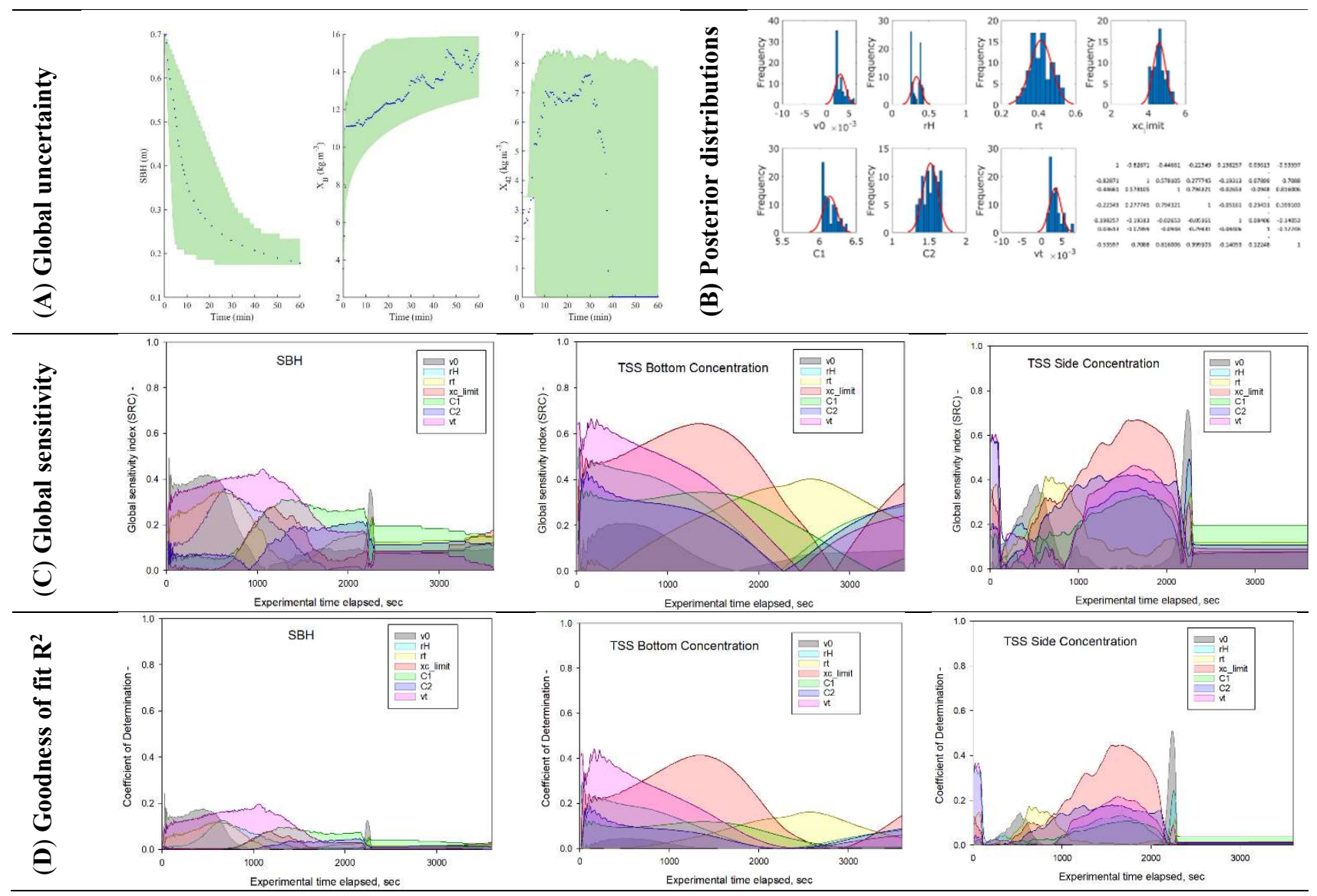

Figure. SI-ii2 Practical model identification using the HTC model; Posterior histograms obtained in 


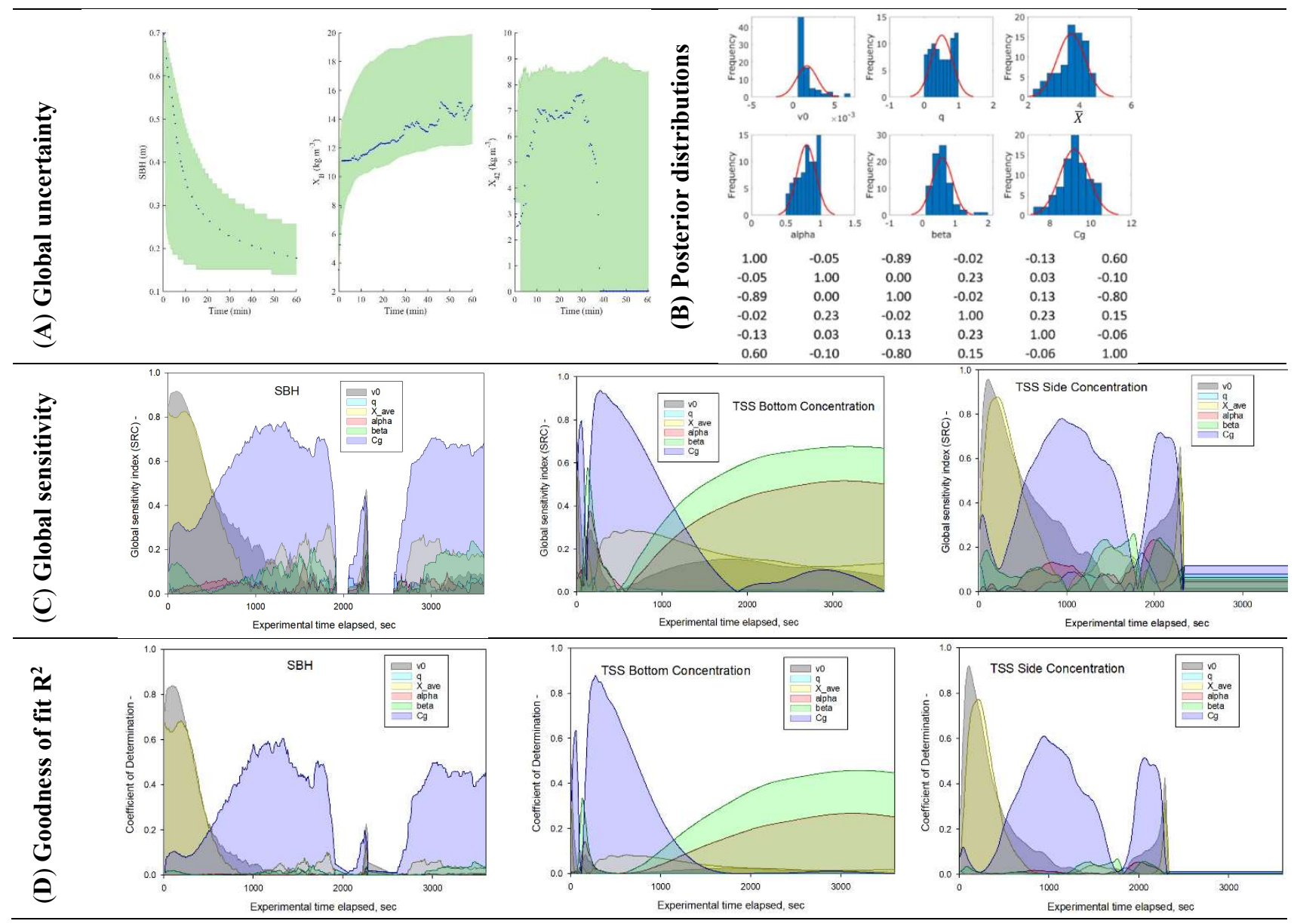

801

802

803

804

805

806

807

Figure. SI-ii3 Practical identifiability test of the Diehl-DeClercq model. Posterior histograms obtained in Step 6@Level 1 (Table 1) as well as values of SRC and Goodness-of-fit for linear regression $\left(\mathrm{R}^{2}\right)$. 
808

809

810

811

\section{Confidence interval as parameter estimator for the new settling} velocity function
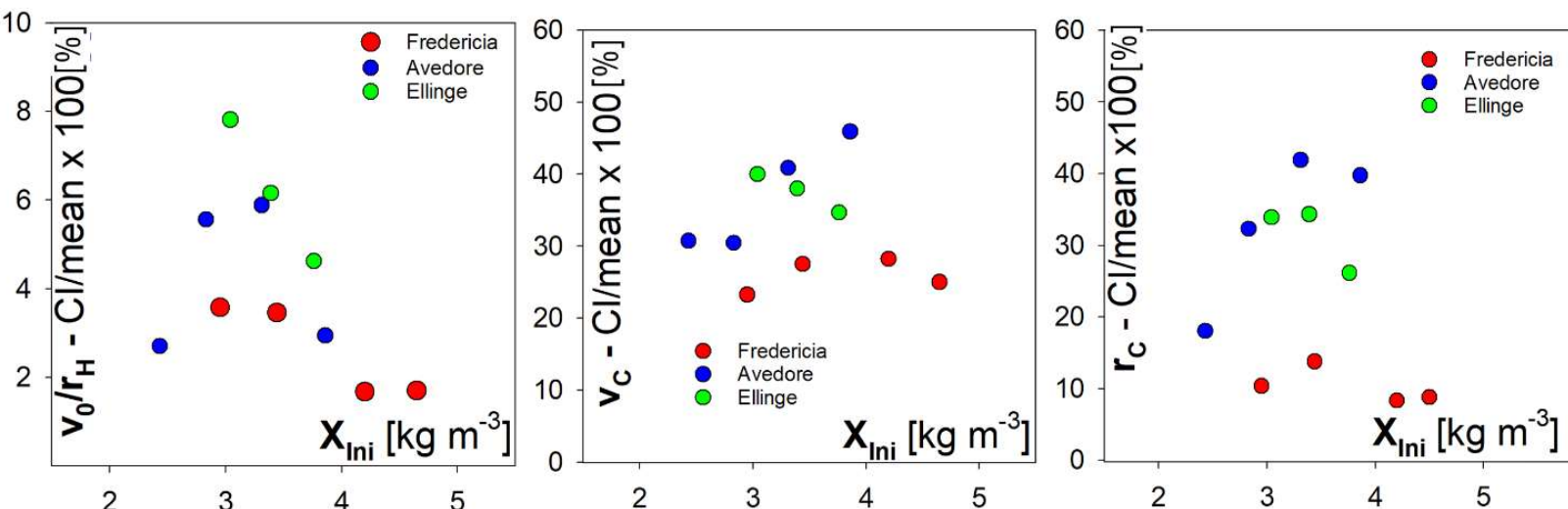

Figure. SI-iii1 Width of confidence intervals, CI [\%] - Values of confidence interval normalised to the mean posterior parameter values estimated times 100 . 


\section{CFD simulations}

\subsection{Full-scale secondary settling tank, OBVA WRRF, Vila-Real, Spain}

A 3-D axi-symmetrical domain was developed for the SST (Circular; diameter: $30 \mathrm{~m}$; Q=22486 $\mathrm{m} 3$ /day). Turbulence was predicted in the simulation model using the Shear Stress Transport model. Transient simulations Herschel-Bulkley model was implemented to predict the rheological behaviour of sludge

$$
\tau=\tau_{0}+K \gamma^{n}
$$

$$
\eta=\frac{\tau}{\gamma}
$$

where $\tau_{0}$ is the yield stress; $K$ is the consistency index; $n$ is the flow behaviour index; and $h$ is the apparent viscosity of sludge. These three variable parameters were calculated using the regression equations

$$
\tau_{0}=A X^{B}
$$

$$
K=\mu_{w} \exp (C \cdot X)
$$

$$
n=\frac{1}{1+D \cdot X^{E}}
$$

where $\mathrm{A}=0.00066\left[\mathrm{~kg}^{1-\mathrm{B}} \mathrm{m}^{3 \cdot \mathrm{B}-1} \mathrm{~s}^{-2}\right], \mathrm{B}=2.18[-], \mathrm{C}=0.28\left[\mathrm{~m}^{3} \mathrm{~kg}^{-1}\right], \mathrm{D}=0.00083\left[\mathrm{~m}^{3 \cdot \mathrm{E}} \mathrm{kg}^{-\mathrm{E}}\right], \mathrm{E}=2.57[-]$ according to Ramin et al. (2014).

For calibrating the hindered settling function, a sequence of six batch settling column tests were carried out onsite (Fig. S1), and the $\mathrm{v}_{0} / \mathrm{r}_{\mathrm{H}}$ parameter value $\left(0.0024 \mathrm{~kg} \mathrm{~m}^{-2} \mathrm{~s}^{-1}\right)$ was estimated by considering $v_{0}=0.0025\left(\mathrm{~m} \mathrm{~s}^{-1}\right)$ and using the exponential regression function, $\mathrm{f}=0.0025^{*} \exp (-$ $\left.r_{H}^{*} \mathrm{X}(\mathrm{i})\right)$ in SigmaPlot 13. The $\mathrm{r}_{\mathrm{H}}$ value obtained is $0.98\left(\mathrm{~m}^{3} \mathrm{~kg}^{-1}\right)$. In the absence of column sensor data in terms of solids concentration in the bottom and side-wall - as proposed in this study - the compressive solid stress was calibrated in the CFD model using the average $v_{C}$ and $r_{C}$ parameter values $\left(0.1\left[\mathrm{~m}^{2} \mathrm{~s}^{-2}\right]\right.$ and $\left.1.5[-]\right)$ obtained for the Avedøre WRRF. This was done based on the $\mathrm{v}_{0} / \mathrm{r}_{\mathrm{H}}$ values and due to the similarity in terms of SVI values obtained in the two WRRFs.

In the on-site measurements, radial velocity was measured using a Vectrino (Nortek, USA) high- 

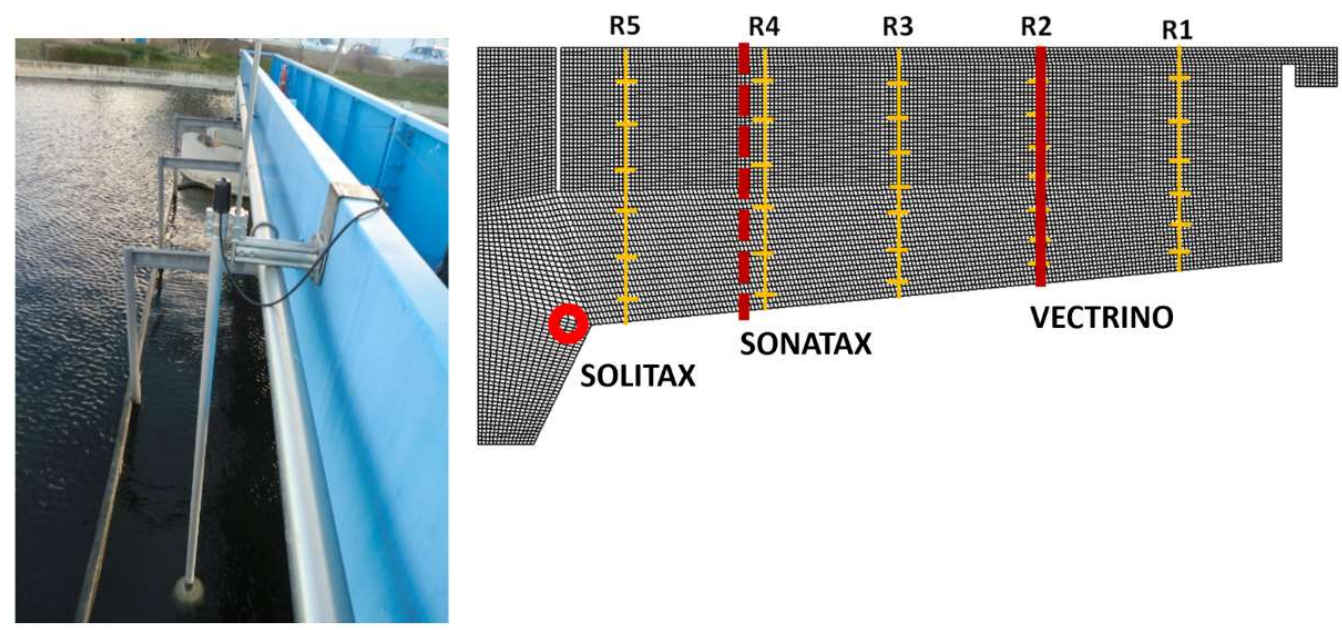

Figure. SI-iv1 The location of velocimeter measurements done in one of the SSTs in the OBVA WRRF, Vila-Real, Spain. Red solid line indicates the position where the velocity meter profile (VECTRINO), shown in Fig. 4, were recorded at. The positions of other sensors including the SONATAX and SOLITAX sensors are indicated with dashed line and circle, respectively.
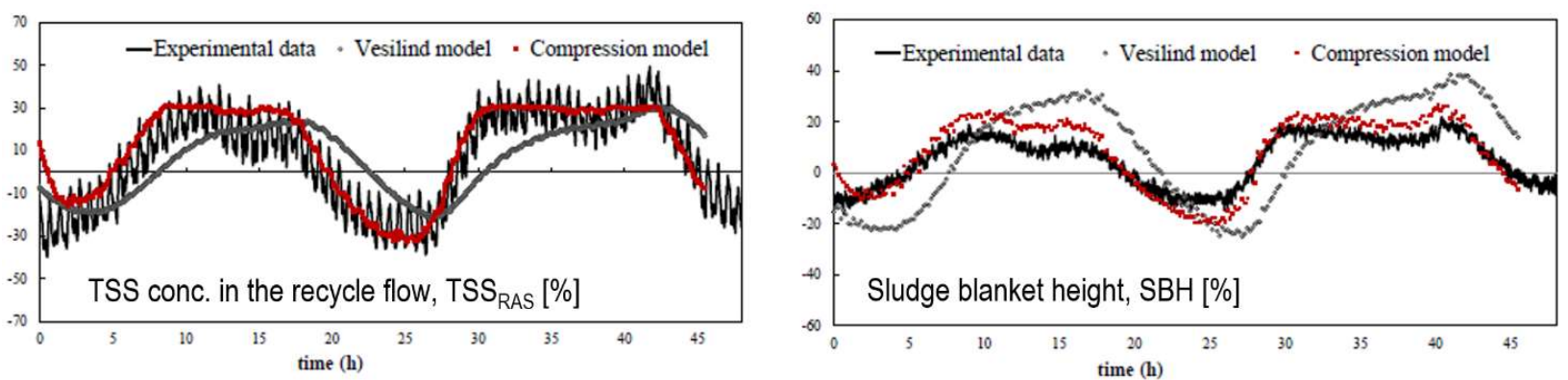

Figure. SI-iv2 Experimental and simulation results obtained in the measurement campaign in the Vila Real WWTP, Spain. \% values were calculated by dividing each value with the mean measured value times 100 . Simulation results were obtained using only Vesilind and the new settling velocity function, including the hindered-compression constitutive functions.

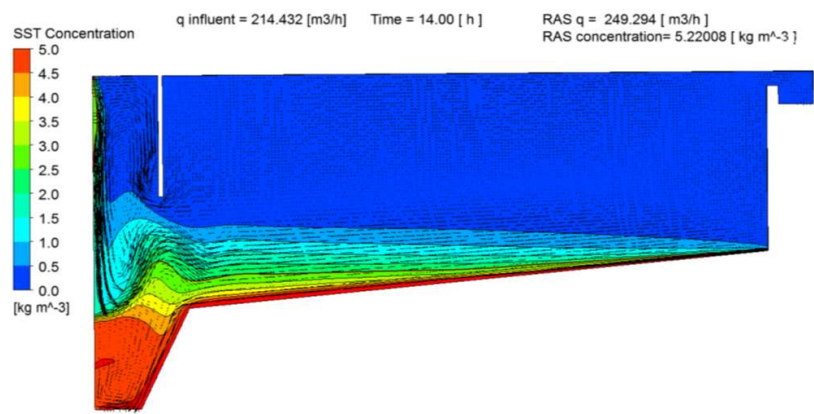

Figure. SI-iv3 TSS performance of the clarifier at $t=14$ hours of the 48 -hour long measurement campaign. 
861

862

863

864

865

866

867

868

869

870

871

872

873

874

875

876

877

878

879

880

881

882

883

884

885

886

887

\subsection{Development of a CFD simulation model of the experimental sludge settling column}

A Computational Fluid Dynamics (CFD) model of the sludge settling column was developed in the commercial software package: ANSYS ${ }^{\circledR}$ CFX. The fundamental two-phase modelling approach used was Eulerian. More specifically, the single-phase Eulerian Drift Flux Model (DFM) was used to describe the behaviour of the dispersed phase (biological flocs) relative to the constrained continuous phase (pure water). The DFM solves a single set of continuity (Eqn. 1) and momentum (Eqn. 2) equations for a fictitious variable composition mixture, with an additional 'drift' equation (Eqn. 3) describing the relative motion of the dispersed to the continuous material. This modelling approach is commonly applied to activated sludge modelling (Brennan, 2001; Ramin et al., 2014).

$$
\begin{gathered}
\frac{\partial \rho_{m}}{\partial t}+\nabla \cdot\left(\rho_{m} v_{m}\right)=0 \\
\frac{\partial \rho_{m} v_{m}}{\partial t}+\nabla \cdot\left(\rho_{m} v_{m} v_{m}\right) \\
=-\nabla \cdot P_{m}+\nabla \cdot\left[\tau+\tau^{t}\right]-\nabla \cdot\left(\frac{\alpha_{d}}{1-\alpha_{d}} \frac{\rho_{c} \rho_{d}}{\rho_{m}} v_{d j} v_{d j}\right)+\rho_{m} g+M_{m} \\
\frac{\partial \alpha_{d}}{\partial t}+\nabla \cdot\left(\alpha_{d} v_{m}\right)=-\nabla \cdot\left(\frac{\alpha_{d} \rho_{c}}{\rho_{m}} v_{d j}\right)+\nabla \cdot \Gamma \nabla \alpha_{d}
\end{gathered}
$$

Implementing the above modelling approach and the Hindered-Compression settling velocity model developed in this stufy, a prototype CFD model of the experimental settling column was produced in ANSYS ${ }^{\circledR}$ CFX. This prototype model used a set of model parameters and activated sludge physical data and could hence be benchmarked against their experimental settling data during the subsequent column meshing studies. These meshing studies considered a column geometry identical to that of the experimental sludge settling column and tested mesh sizes ranging from coarse $(3,360$ elements $)$ to very-fine $(57,288)$. It was concluded that the medium mesh size, comprising 7,708 elements, resulted in an accurate reproduction of experimental data while minimising computational effort and avoiding issues associated with numerical instability and poor convergence in near-wall regions experienced when using a very-fine mesh.
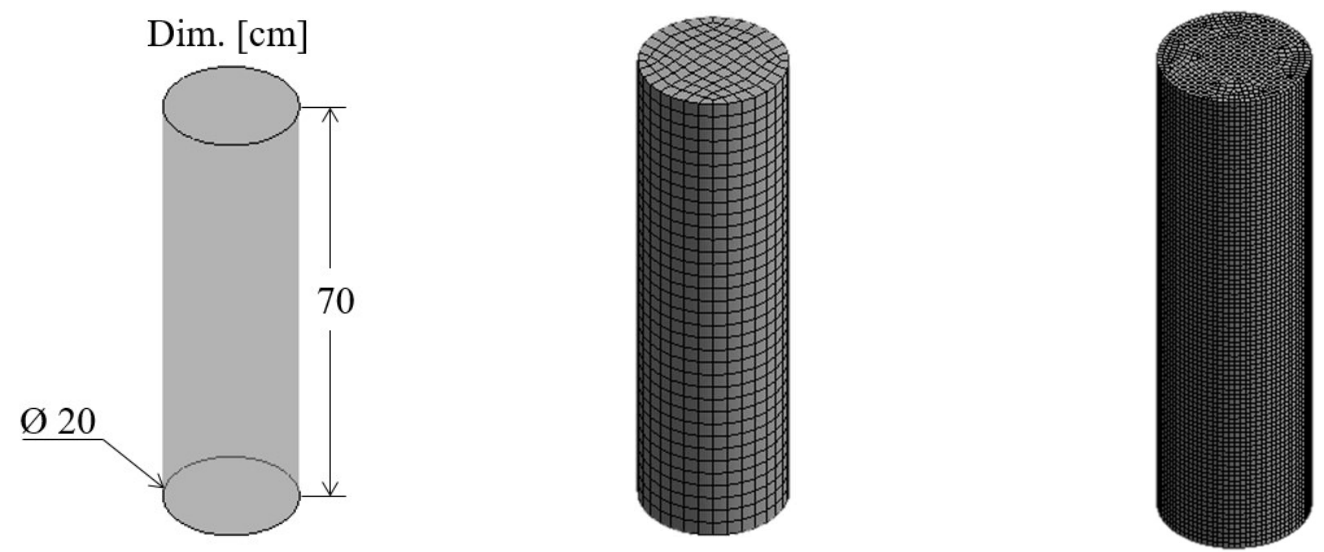

Figure. SI-iv4 The basic column geometry considered for the CFD model, (3.1) the coarsest ('coarse') column mesh tested (3,360 elements), (3.2) the finest ('very-fine') column mesh tested $(57,288$ elements)

In further developing the sludge settling column CFD model, it was necessary to consider both the sludge rheology and turbulence modelling approaches taken. This was done via scenario simulation, once again using the experimental data as a benchmark for sludge blanket height (SBH) and sludge 
concentration at the bottom $\left(X_{B}\right)$ and side $\left(X_{\text {side }}\right)$ of the column over the course of the 60 minute settling experiment. It was determined, by the comparison of a simple Newtonian viscosity model and the non-Newtonian Ostwald de Waele or Power Law model, that the treatment of sludge rheology in the CFD model had little to no impact on the accuracy with which experimental data sets could be replicated. For this reason, the simpler Newtonian model was adopted to minimise the complexity of the simulation. Alternatively, the chosen turbulence modelling approach was found to greatly impact the replication of experimental $\mathrm{SBH}, X_{B}$ and $X_{\text {side }}$ profiles, particularly within the so-called 'lag-phase' at the commencement of the settling experiment. The Re-Normalisation Group (Yakhot et al., 1992) and Shear Stress Transport (Menter, 1994) k- $\varepsilon$ derivatives were compared via scenario simulation and the latter found far superior with regard to the present application, particularly in the prediction of $X_{\text {side }}$. 
901

902

903

904

905

906

907

908

909

910

911

912

913

914

915

916

917

918

919

920

921

922

923

924

925

\section{Compression settling and compression solids concentration}

For modelling of the onset of compression settling, Guyonvarch et al. (2015) assess the setting of the variable compressive threshold concentration $\left(X_{C}\right)$ using state-of-the-art models (Bürger et al., 2013; Ramin et al., 2014; De Clercq, 2006, De Clercq et al., 2008). Based on the relative predictive error, computational time and a separate model validation test, the approach of setting $X_{C}$ as a function of the initial solid concentration and the SST feed concentration for simulating batch tests and SST, respectively, is found superior over other methods.

Notably, the two models of time-dependent $X_{C}$ by DeClercq (2006) are of interest as they are identified based on in-depth radiotracer experiemental data, i.e. (a) $X_{C}=X_{S B H+5}$ where $X_{S B H+5}$ is the concentration of the layer located 5 layers below the top of the sludge blanket (De Clercq, 2006); and (b) the concentration of the highest layer within the sludge blanket where the concentration gradient falls below $200 \mathrm{~g} / \mathrm{L} / \mathrm{m}$ (De Clercq et al., 2008). It is noteworthy that both of these models failed the discrimination tests (Table SI-v.1), which partly promted the present research as well.

Table SI-v.1 Comparison of different second-order 1-D-model structures in terms of feed-layer location and compression threshold concentration - a model discrimination study carried out by Guyonvarch et al. (2015). For the discretization of the Model 0, 90 layers are used and pseudodispersion $\mathrm{D}_{\mathrm{f}}$ is considered only around the feed layer, at a distance $\min \left(H_{\text {in }} ; S W D-H_{\text {in }}\right) / 2$ (Bürger et al., 2013). For Model 1 to 8, the number of layers used is 60 layers and a single pseudo-dispersion $\mathrm{D}_{0}$ constant along the tank (Plósz et al., 2007). For more details on the validation test, see Chapter 2.3.3 in Guyonvarch et al. (2015). ${ }^{a}$ - Computational time evaluation is expressed as Low (few seconds), High (hours) and Too high (up to several days). An Acceptable computational time is considered from several seconds to few minutes. ${ }^{b}$ - The validation test is considered as failed if the mean SSRE between 1-D model predictions and CFD outputs is significantly higher than 1.

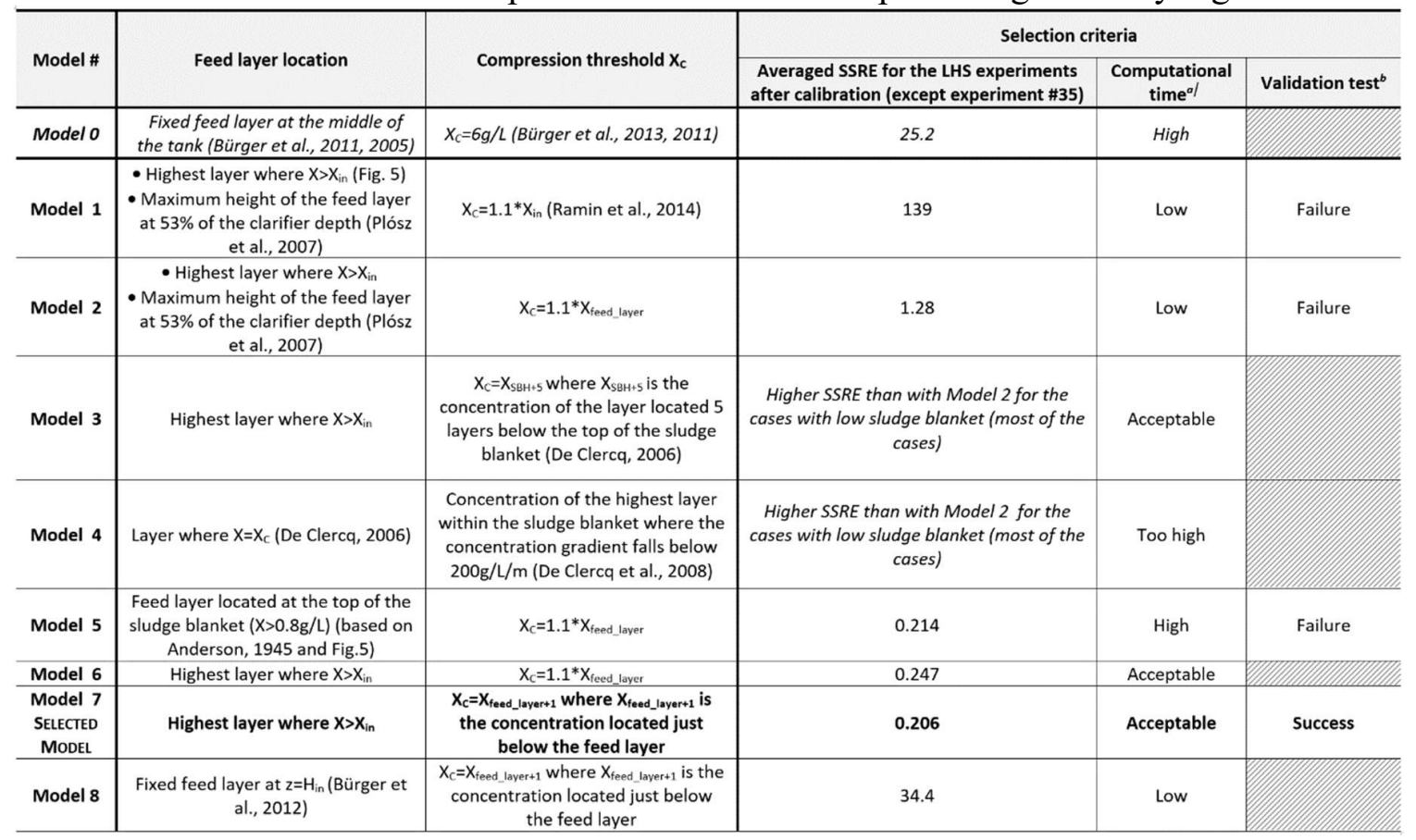

Theoretically, the solid concentration in the volume of slurry settling in the hindered regime in a settling column test corresponds to that of the initial concentration. Any increase of the local 
degree of solid stress through interactions with the increasing cake in the bottom of batch column (Fig. SI.v.2). According to Kynch's theory, in the falling hindered settling rate region, also referred to as transient settling, straight isoconcentration lines propagate from the bottom of the cylinder. Furthermore, tangential isoconcentration lines propagate from the sediment-suspension interface during compression settling. Straight isoconcentration lines suggest a first-order process, same as hindered settling, whereas the curved isoconcentration lines indicate a second-order phenomenon, i.e. compression settling.

DeClercq (2006) suggest modelling sedimentation transport by considering only hindered and compression settling, and by employing a time-dependent onset of compression through the aforementioned $X_{C}$ models.

Partly because DeClercq (2006)'s models seem to overestimate the transient settling velocity and due to challenges in implementing the proposed $X_{C}$ models in SST simulation models, Ramin et al. (2014) propose a model that additionally includes a first-order transient settling function, formulated analogously to hindered settling (straight isoconcentration lines), and by employing two threshold concentrations for the onset of transient $\left(X_{T}\right)$ and then for compression settling, $X_{C}$.

In contrast to these previous approaches, besides the hindered settling, the present paper proposes a compression settling function to predict any effects of solid stress propagating through the sludge blanket (i) by setting $X_{C}=X_{I n i}$ and (ii) by formulating the solids stress independently from the $X_{C}$ value and from the relative concentration $\left(X-X_{C}\right)$ that can allow first-order solid settling behaviour to occur at relatively low $X$.

Additionally, the physical justification for setting $X_{C}$ at the feed solid concentration for SST modelling is that the density current of the feed slurry tends towards zero buoyancy, and propagates through volumes, under which, the descending particles shall increase the local concentration only if they exhibit compressive solids settling (Fig. SI.v.3; Guyonvarch et al., 2015).
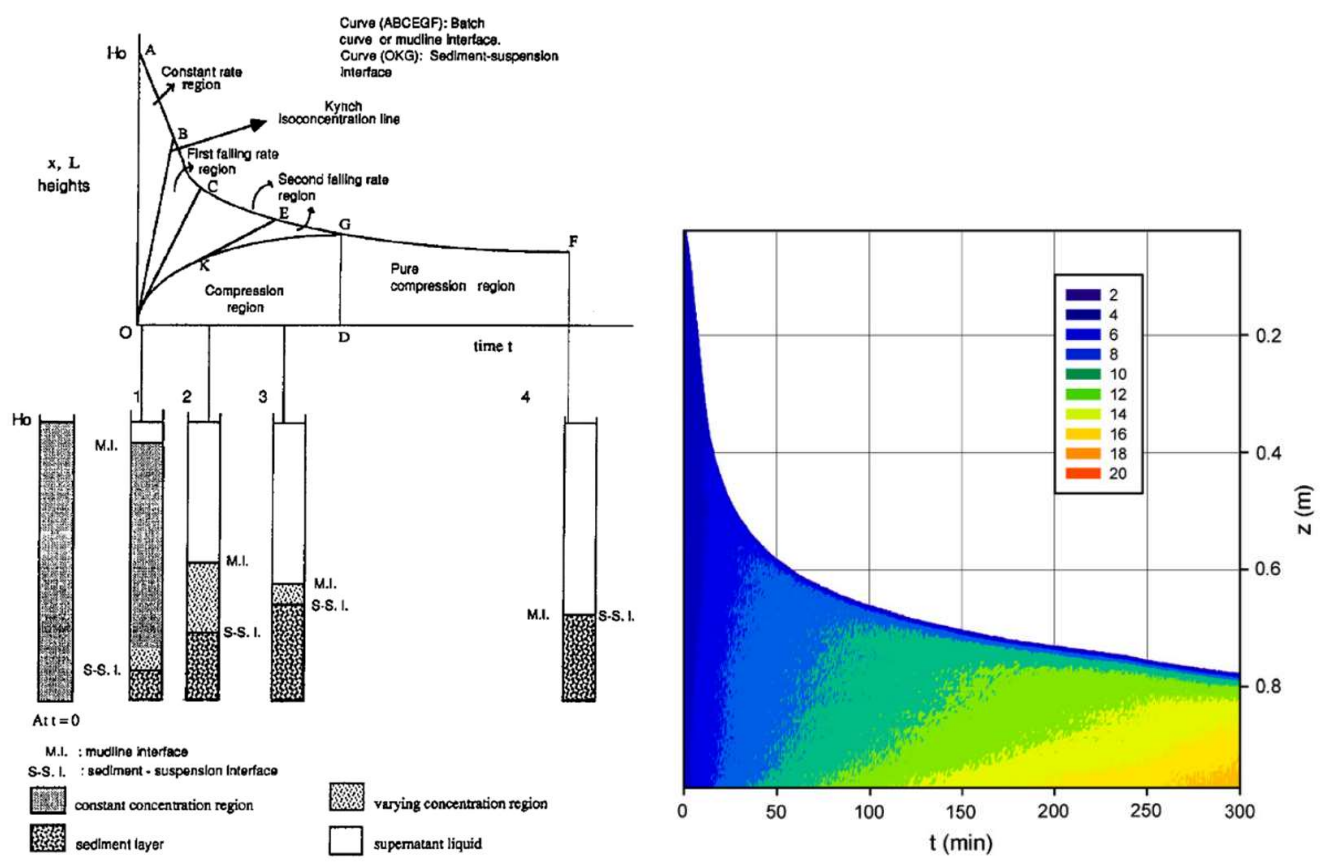

Figure SI.v.2. Solid sedimentation - (left) Theory according to (Diplas and Papanicolaou, 1997) and (right) measurements according to DeClercq et al. (2008) - Iso-concentration contour plot during batch settling of Destelbergen Sludge. 


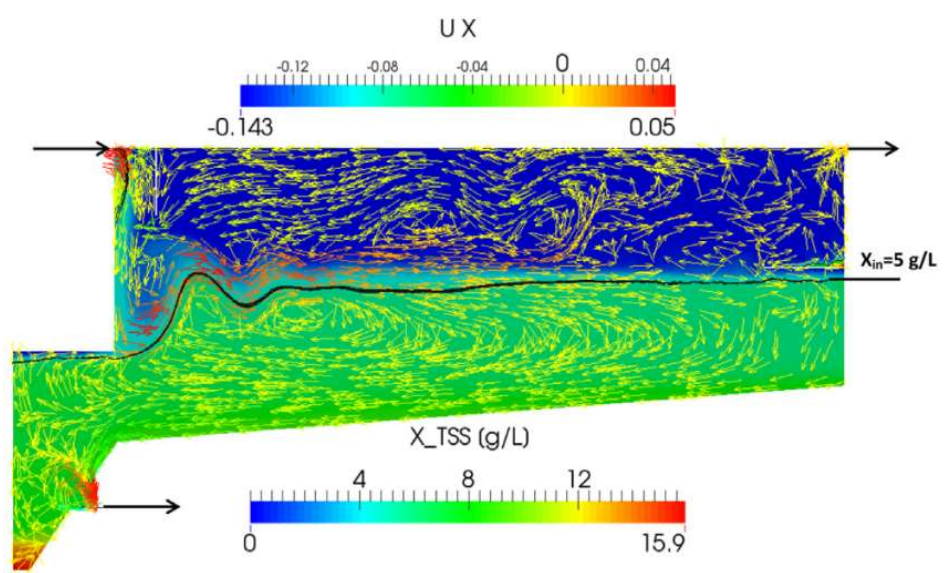

Figure SI.v.3. The SST influent density current - the rationale for the $X_{C}$ modeling approach in CFD as well as feed-layer selection in 1-D SST modelling (Guyonvarch et al., 2015). The velocity vectors (arrows) are coloured according to the magnitude of the horizontal velocity component (UX in $\mathrm{m} / \mathrm{s}$ ) - not scaled according to the velocity magnitude. $X(\mathrm{~g} / \mathrm{L})$ is represented across the tank, and the iso-contour corresponds to the inlet/feed concentration $X_{\text {Feed }}$ (solid black line).

\section{References}

Brennan, D., 2001. The numerical simulation of two phase flows in settling tanks. Imperial College London (University of London).

De Clercq, J., 2006. Batch and continuous settling of activated sludge: in-depth monitoring and 1-D compression modelling. Ph.D. Thesis, University of Gent, Belgium.

De Clercq, J., Nopens, I., Defrancq, J., Vanrolleghem, P.A., (2008). Extending and calibrating a mechanistic hindered and compression settling model for activated sludge using in-depth batch experiments. Water Res. 42 (3), 781-791.

Diplas, P., Papanicolaou, A.N., 1997. Batch analysis of slurries in zone settling regime. J. Environ. Eng. 123, 659-667.

Diehl., S., (2008). The solids-flux theory - confirmation and extension by using partial differential equations. Water Res. 42, 4976-4988.

Guyonvarch, E., Ramin, E., Kulahci, M., Plósz, B.G. 2015. iCFD: Interpreted computational fluid dynamics - Degeneration of CFD to one-dimensional advection-dispersion models using statistical experimental design - The secondary clarifier. Water Research 83, 396-411.

Menter, F.R., 1994. 2-Equation Eddy-Viscosity Turbulence Models for Engineering Applications. Aiaa Journal, 32(8), pp. 1598-1605.

Ramin, E., Wágner, D.S., Yde, L., Binning, P.J., Rasmussen, M.R., Mikkelsen, P.S., Plósz, B.G. (2014b). A new settling velocity model to describe secondary sedimentation. Water Research 66, 447-458.

Torfs, E., Balemans, S., Locatelli, F., Diehl, S., Bürger, R., Laurent, J., Francois, P., Nopens, I., (2017). On constitutive functions for hindered settling velocity in 1-D settler models: selection of appropriate model structure. Water Research 110, 38-47.

Valverde-Perez, B., Penkarski-Rodon, E., Wagner, D. and Plosz, B., 2016. Secondary settling sensor setup development - testing prototypes and compression models via practical model parameter identifiability assessmentIWA Specialist Conference: Advances in particle science and separation, Oslo, Norway.

Vesilind, P.A., (1968). Design of prototype thickeners from batch settling tests. Water Sewage Works 
$115,302-307$.

999 Yakhot, V., Orszag, S.A., Thangam, S., Gatski, T.B. and Speziale, C.G., 1992. Development of 1000 Turbulence Models for Shear Flows by a Double Expansion Technique. Physics of Fluids a$1001 \quad$ Fluid Dynamics, 4(7), pp. 1510-1520. 
1006 1007

1008

1012

1013

1014

\section{Figures specifically referred to in the main body of text}

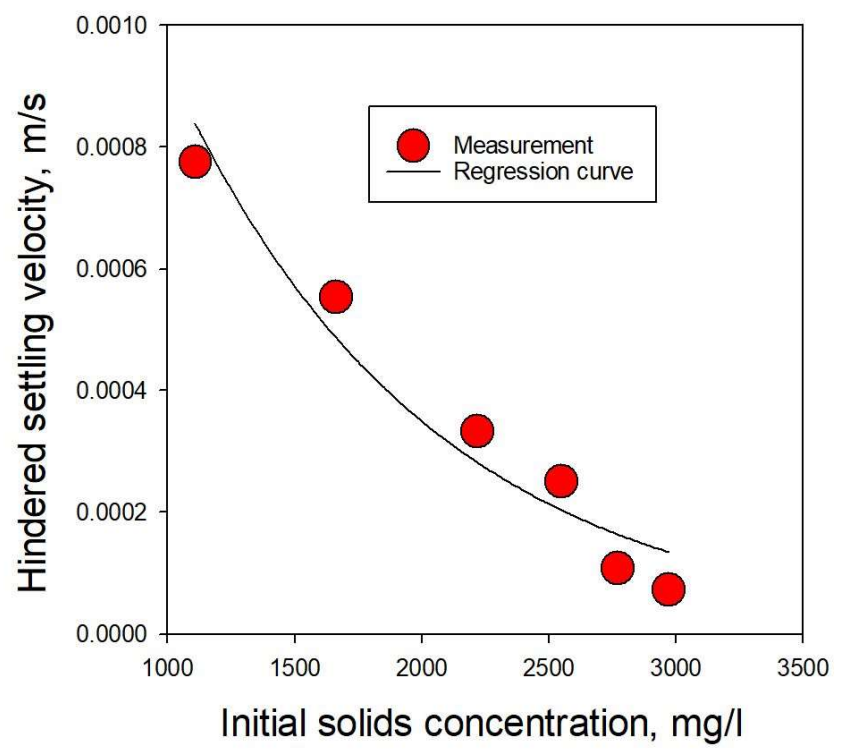

Figure S1. Hindered settling velocity model calibration in the CFD simulation model using 6 dilutions of activated sludge samples in the full-scale secondary settling tank, OBVA WRRF, VilaReal, Spain. 


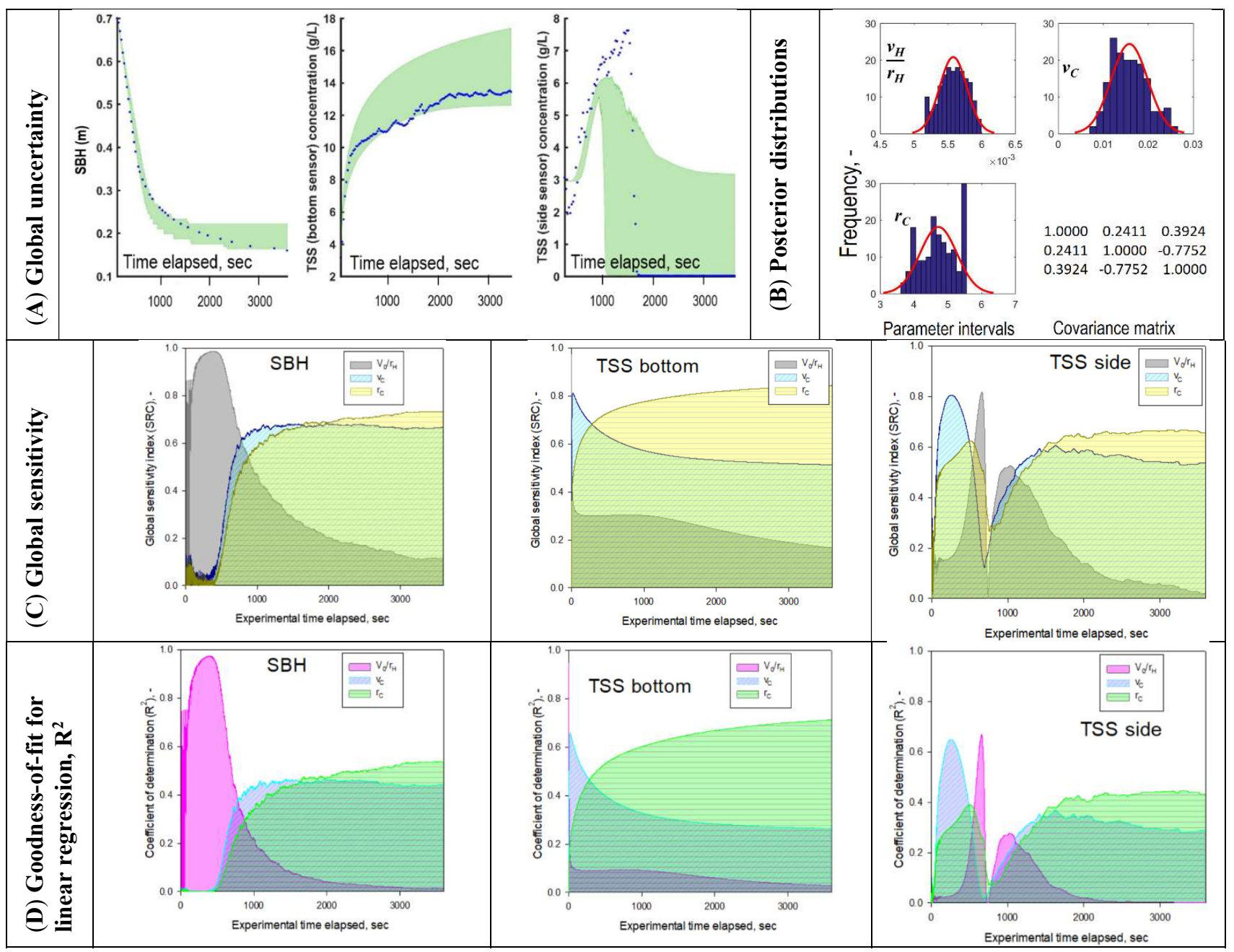

1015 Figure S2. Practical model identification using data obtained with well-settling solids - measured and simulated data for activated sludge collected in Fredericia WRRF using the new hinderedcompression process model; Initial solid concentration: $2.95 \mathrm{~g} \mathrm{~L}^{-1}$; Proposed/a priori probability ranges: $\mathrm{v}_{0} / \mathrm{r}_{\mathrm{H}}=[0.0050 .0062] ; \mathrm{v}_{\mathrm{C}}=[0.0050 .027] ; \mathrm{r}_{\mathrm{C}}=[2.55 .5]$; Global uncertainty plots with $95 \%$ confidence intervals, posterior parameter density distributions, values of dynamic global sensitivity (SRC) and Goodness-of-fit for linear regression $\left(\mathrm{R}^{2}\right)$ computed for $\mathrm{SBH}$, TSS bottom and side concentration state-variables. 


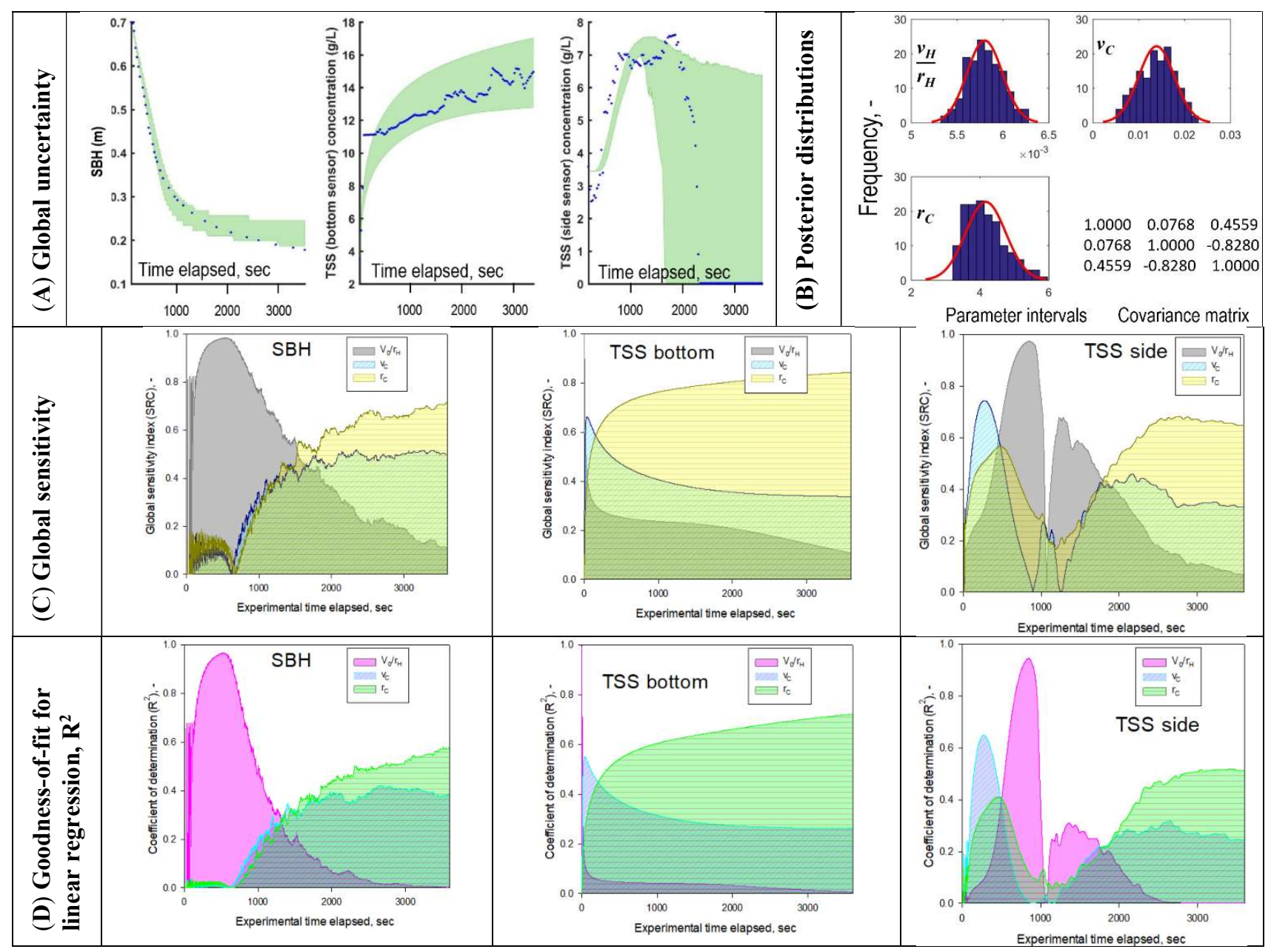

Figure S3 Practical model identification using data obtained with well-settling solids - measured and simulated data for activated sludge collected in Fredericia WRRF using the new hinderedcompression process model; Initial solid concentration: $3.44 \mathrm{~g} \mathrm{~L}^{-1}$; Proposed/a priori probability ranges: $v_{0} / r_{H}=[0.00520 .0063] ; v_{C}=[0.0050 .025] ; r_{C}=[2.55 .5]$; Global uncertainty plots with $95 \%$ confidence intervals, posterior parameter density distributions, values of dynamic global sensitivity (SRC) and Goodness-of-fit for linear regression $\left(\mathrm{R}^{2}\right)$ computed for SBH, TSS bottom and side concentration state-variables. 

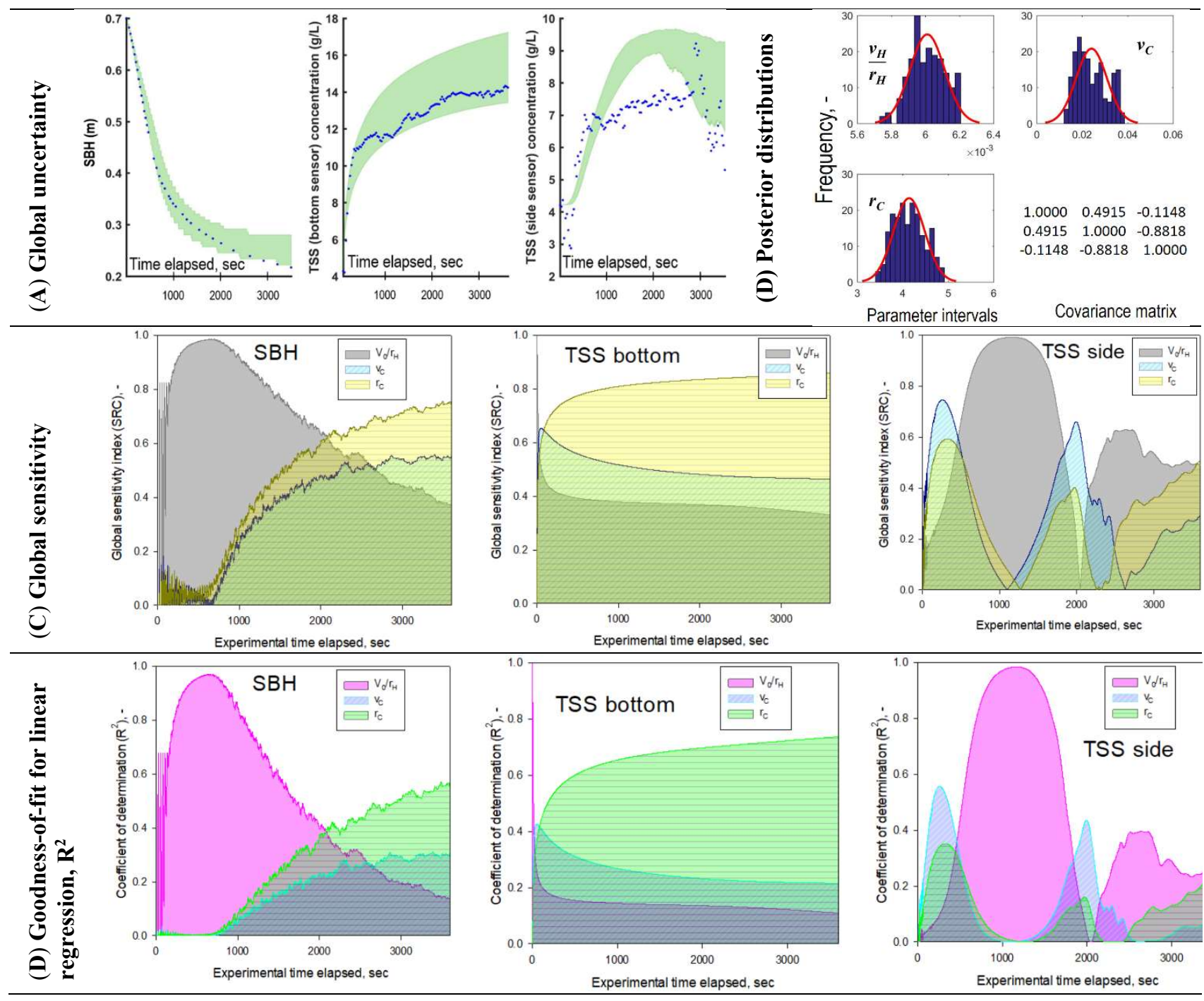

Figure S4. Practical model identification using data obtained with well-settling solids - measured and simulated data for activated sludge collected in Fredericia WRRF using the new hinderedcompression process model; Initial solid concentration: $4.2 \mathrm{~g} \mathrm{~L}^{-1}$; Proposed/a priori probability ranges: $v_{0} / r_{H}=[0.00520 .0063] ; v_{C}=[0.0050 .025] ; r_{C}=[2.55 .5]$; Global uncertainty plots with $95 \%$ confidence intervals, posterior parameter density distributions, values of dynamic global sensitivity (SRC) and Goodness-of-fit for linear regression $\left(\mathrm{R}^{2}\right)$ computed for SBH, TSS bottom and side concentration state-variables. 


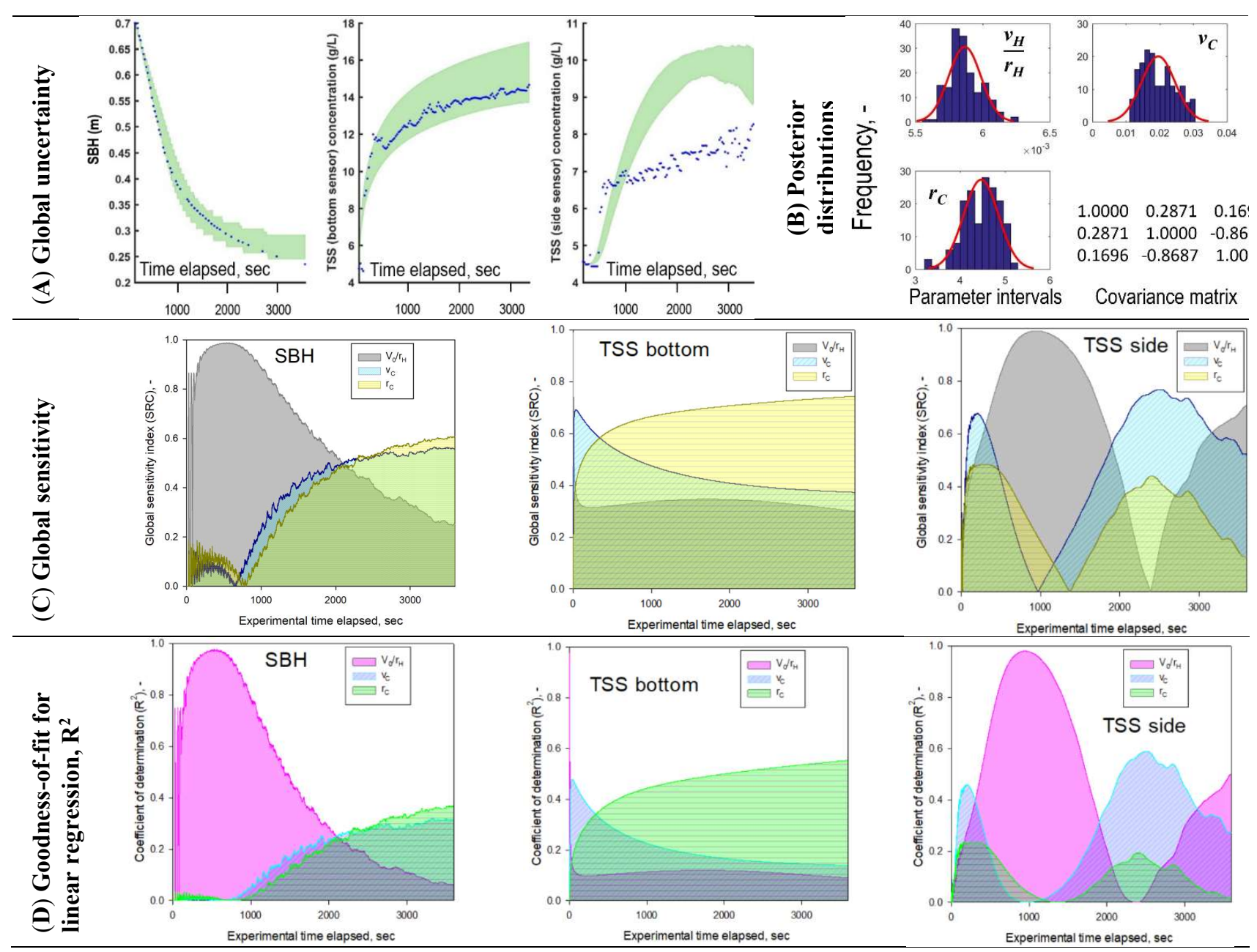

1046

Figure S5. Practical model identification using data obtained with well-settling solids - measured and simulated data for activated sludge collected in Fredericia WRRF using the new hinderedcompression process model; Initial solid concentration: $4.5 \mathrm{~g} \mathrm{~L}^{-1}$; Proposed/a priori probability ranges: $v_{0} / r_{H}=[0.00520 .0063] ; v_{C}=[0.0050 .025] ; r_{C}=[2.55 .5]$; Global uncertainty plots with $95 \%$ confidence intervals, posterior parameter density distributions, values of dynamic global sensitivity (SRC) and Goodness-of-fit for linear regression $\left(\mathrm{R}^{2}\right)$ computed for SBH, TSS bottom and side concentration state-variables. 

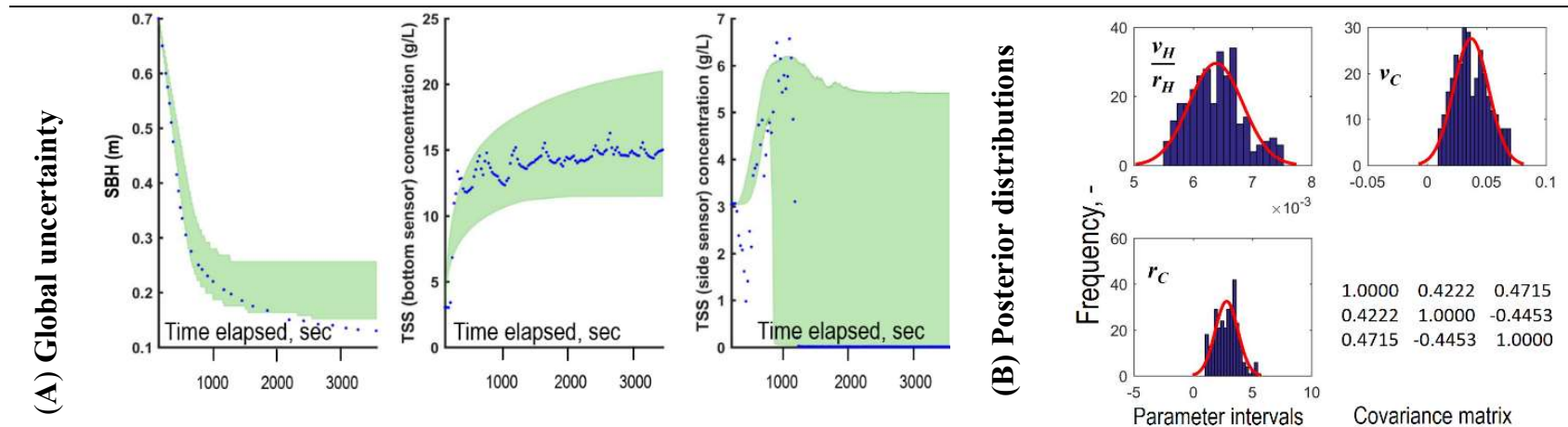

$\begin{array}{lll}1.0000 & 0.4222 & 0.4715\end{array}$

$\begin{array}{llll}0.4222 & 1.0000 & -0.4453\end{array}$

$\begin{array}{lll}0.4715 & -0.4453 & 1.0000\end{array}$
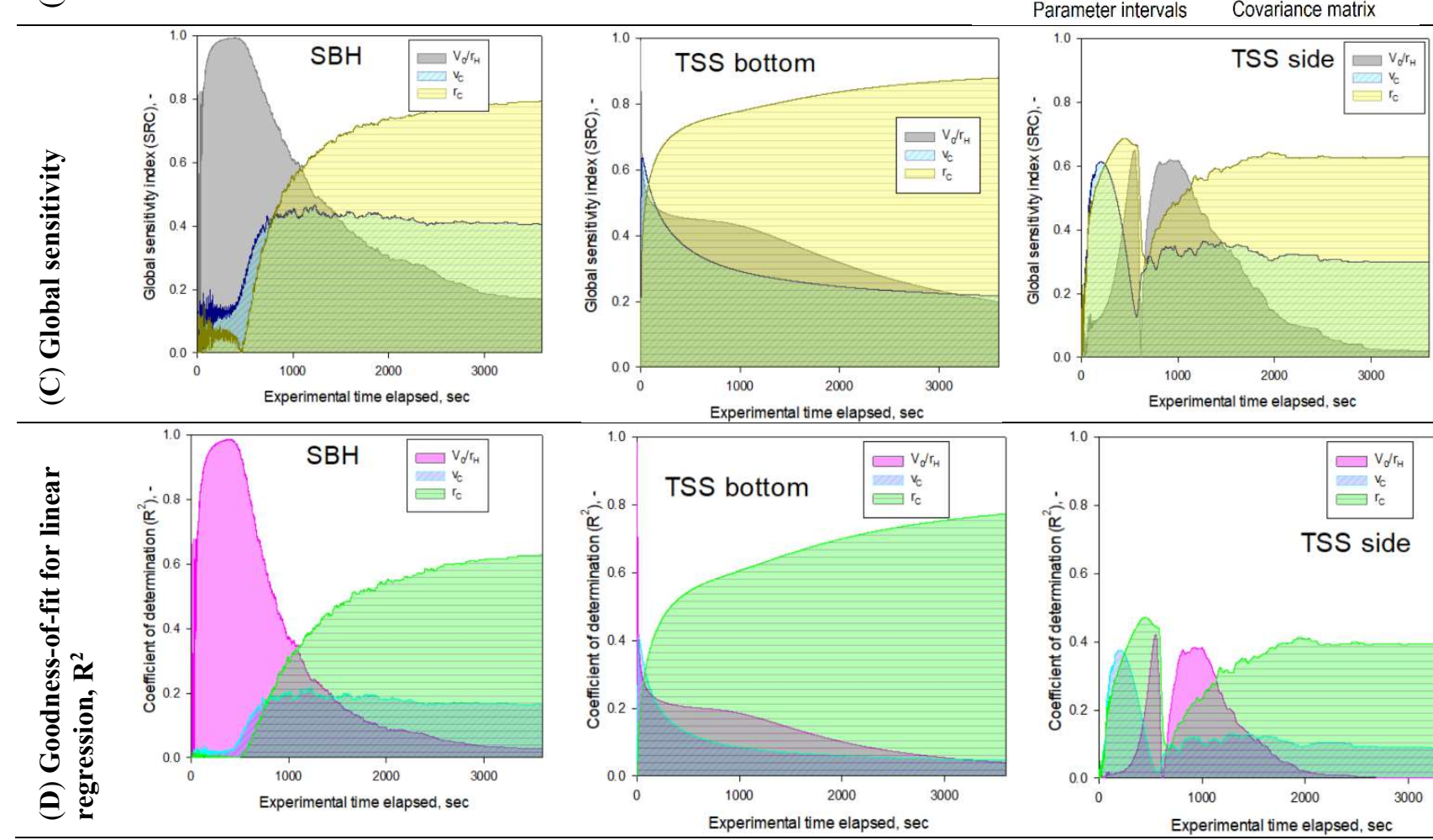

Figure S6. Model validation using data obtained with well-settling solids - measured and simulated data for activated sludge collected in Ellinge WRRF using the new hindered-compression process model; Initial solid concentration: $3.0 \mathrm{~g} \mathrm{~L}^{-1}$; Proposed/a priori probability ranges: $v_{0} / r_{H}=[0.0051$ $0.0076] ; v_{C}=[0.010 .07] ; r_{C}=[0.56]$; Global uncertainty plots with $95 \%$ confidence intervals, posterior parameter density distributions, values of dynamic global sensitivity (SRC) and Goodness-of-fit for linear regression $\left(\mathrm{R}^{2}\right)$ computed for SBH, TSS bottom and side concentration state-variables. 


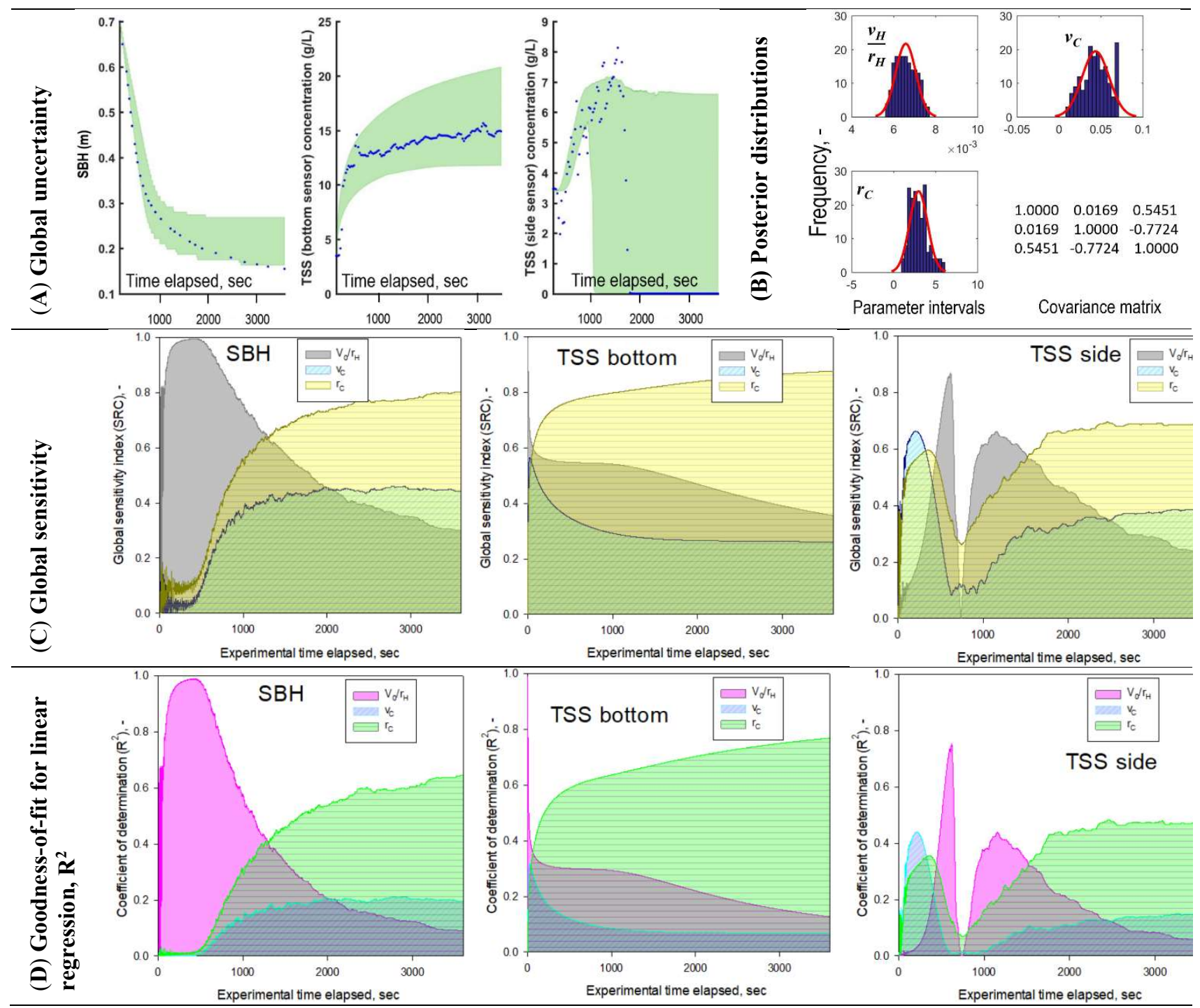

Figure S7. Model validation using data obtained with well-settling solids - measured and simulated data for activated sludge collected in Ellinge WRRF using the new hindered-compression process model; Initial solid concentration: $3.4 \mathrm{~g} \mathrm{~L}^{-1}$; Proposed/a priori probability ranges: $v_{0} / r_{H}=[0.005$ $0.0077] ; v_{C}=[0.010 .07] ; r_{C}=[0.56]$; Global uncertainty plots with $95 \%$ confidence intervals, posterior parameter density distributions, values of dynamic global sensitivity (SRC) and Goodness-of-fit for linear regression $\left(\mathrm{R}^{2}\right)$ computed for SBH, TSS bottom and side concentration state-variables. 


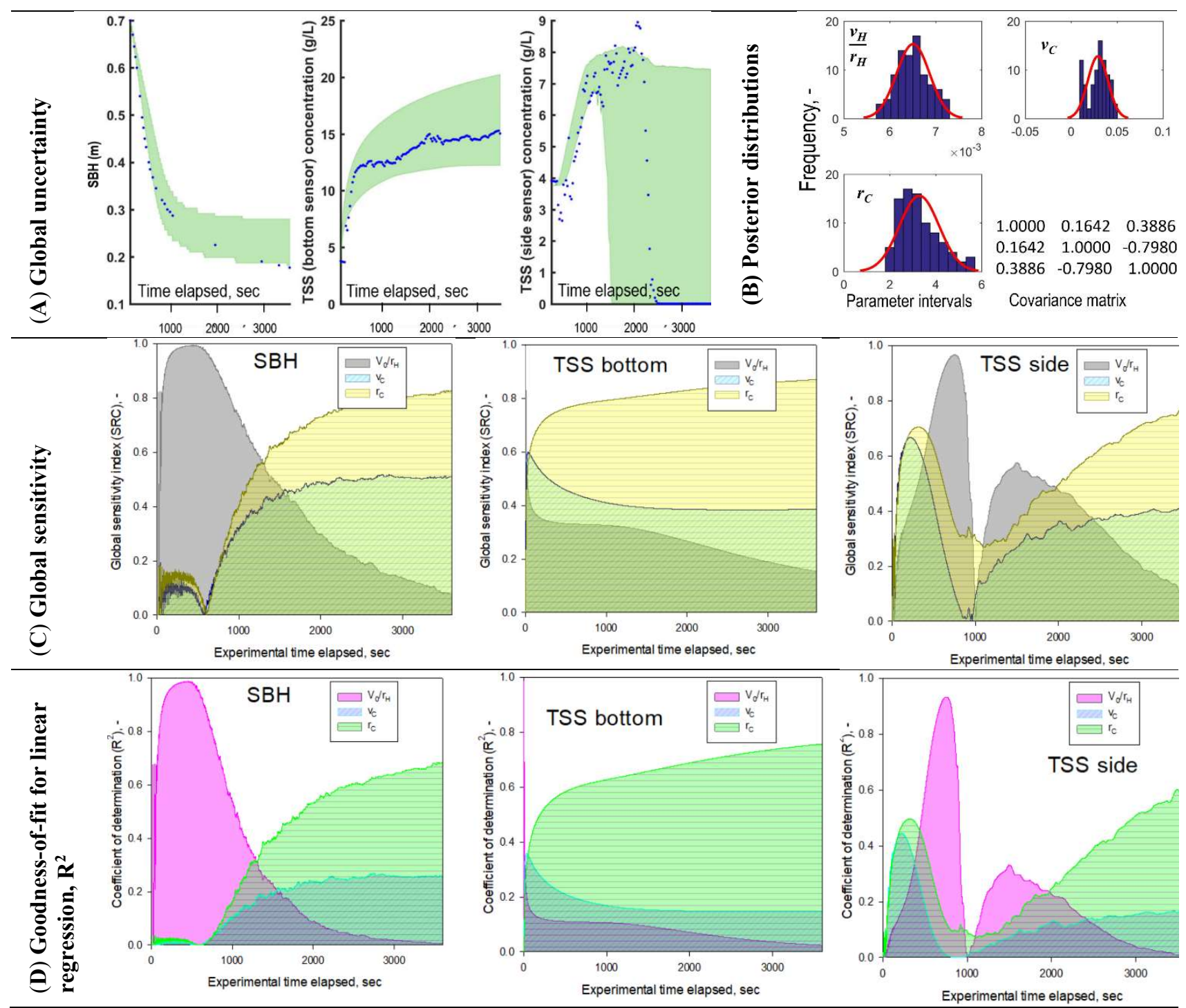

Figure S8. Model validation using data obtained with well-settling solids - measured and simulated data for activated sludge collected in Ellinge WRRF using the new hindered-compression process model; Initial solid concentration: $3.8 \mathrm{~g} \mathrm{~L}^{-1}$; Proposed/a priori probability ranges: $v_{0} / r_{H}=[0.0051$ $0.0075] ; v_{C}=[0.010 .07] ; r_{C}=[0.86]$; Global uncertainty plots with $95 \%$ confidence intervals, posterior parameter density distributions, values of dynamic global sensitivity (SRC) and Goodness-of-fit for linear regression $\left(\mathrm{R}^{2}\right)$ computed for SBH, TSS bottom and side concentration state-variables. 


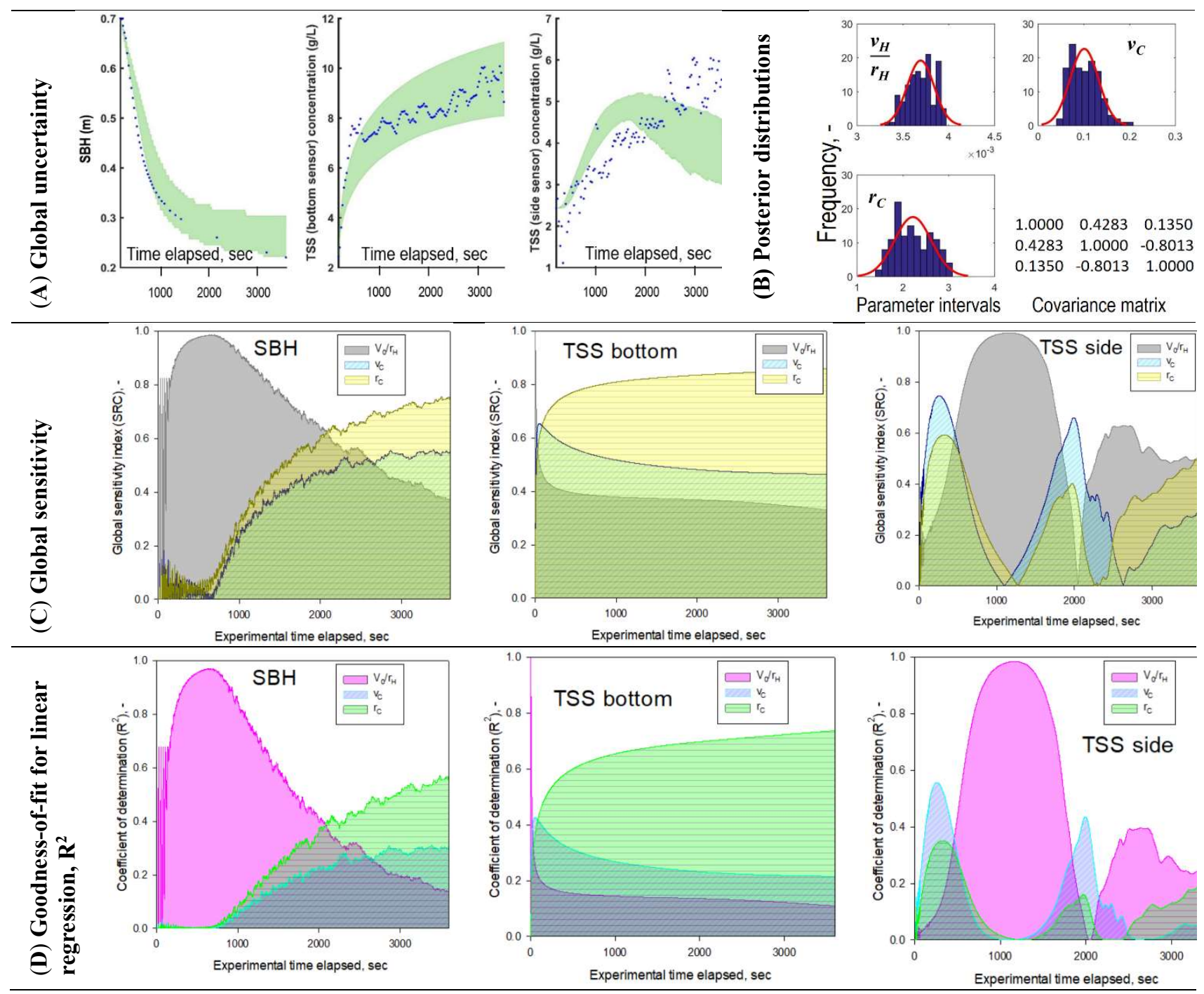

1091

Figure S9. Model validation using data obtained with filamentous bulking solids - measured and simulated data for activated sludge collected in Avedøre WRRF using the new hinderedcompression process model; Initial solid concentration: $2.4 \mathrm{~g} \mathrm{~L}^{-1}$; Proposed/a priori probability ranges: $v_{0} / r_{H}=[0.0030 .004] ; v_{C}=[0.020 .2] ; r_{C}=\left[\begin{array}{ll}0.5 & 3\end{array}\right]$; Global uncertainty plots with $95 \%$ confidence intervals, posterior parameter density distributions, values of dynamic global sensitivity (SRC) and Goodness-of-fit for linear regression $\left(\mathrm{R}^{2}\right)$ computed for SBH, TSS bottom and side concentration state-variables. 

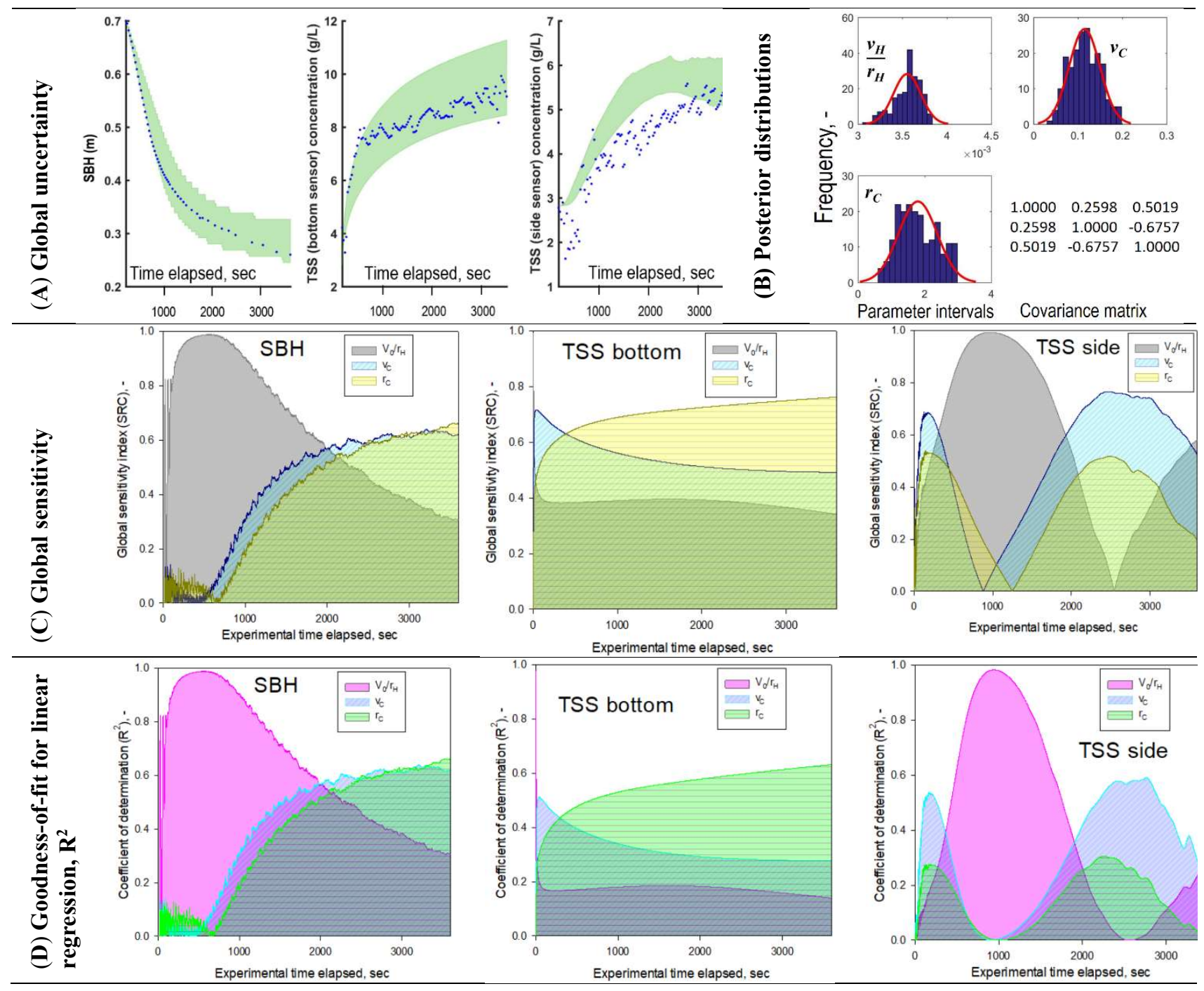

1102

1103

1104

1105

1106

1107

1108

1109

1110
Figure S10. Model validation using data obtained with filamentous bulking solids - measured and simulated data for activated sludge collected in Avedøre WRRF using the new hinderedcompression process model; Initial solid concentration: $2.8 \mathrm{~g} \mathrm{~L}^{-1}$; Proposed/a priori probability ranges: $v_{0} / r_{H}=[0.0030 .004] ; v_{C}=[0.020 .2] ; r_{C}=[0.54]$; Global uncertainty plots with $95 \%$ confidence intervals, posterior parameter density distributions, values of dynamic global sensitivity (SRC) and Goodness-of-fit for linear regression $\left(\mathrm{R}^{2}\right)$ computed for SBH, TSS bottom and side concentration state-variables. 


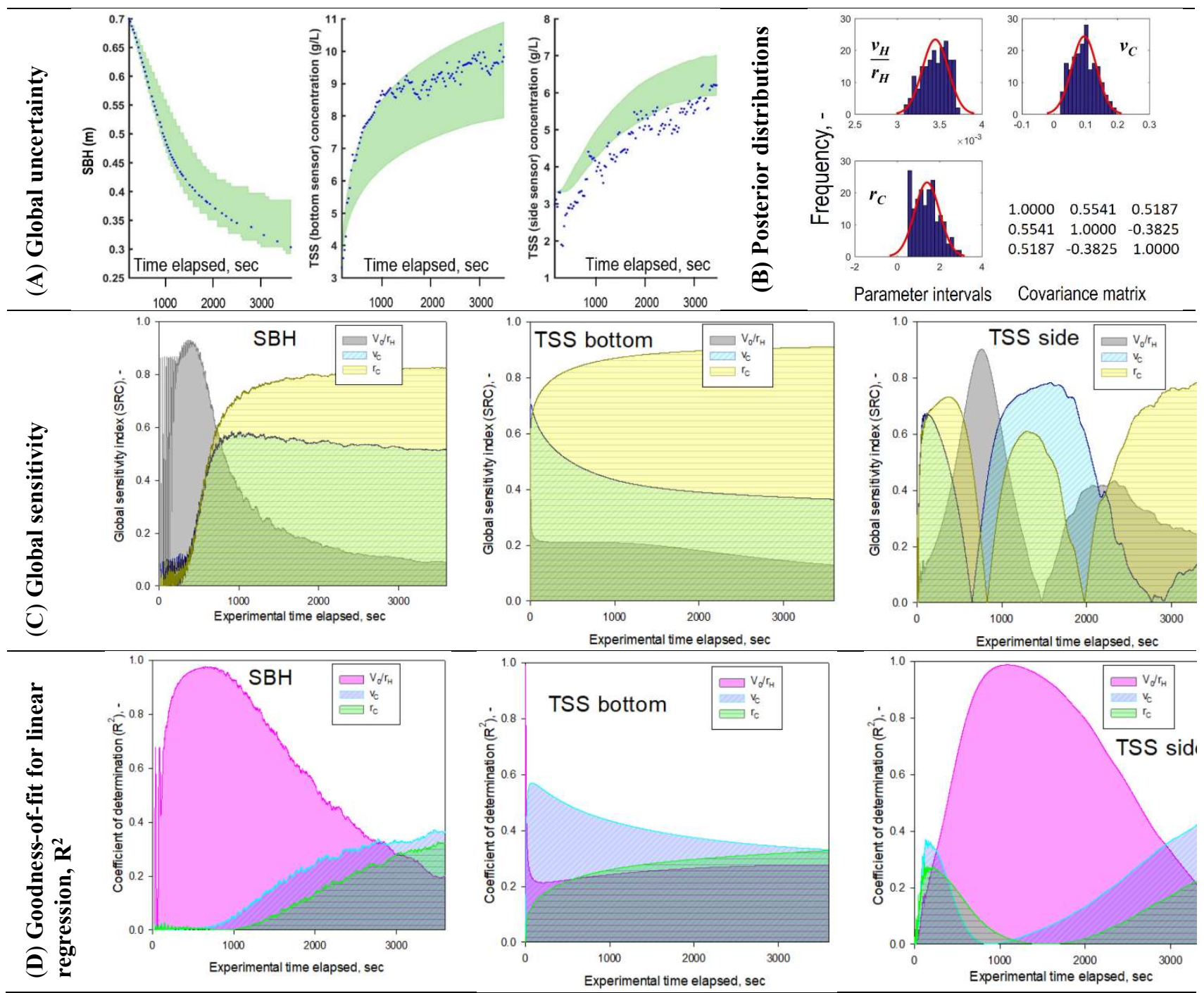

1112
Figure S11. Model validation using data obtained with filamentous bulking solids - measured and simulated data for activated sludge collected in Avedøre WRRF using the new hinderedcompression process model; Initial solid concentration: $3.3 \mathrm{~g} \mathrm{~L}^{-1}$; Proposed/a priori probability ranges: $v_{0} / r_{H}=[0.0030 .004] ; v_{C}=[0.020 .2] ; r_{C}=[0.84]$; Global uncertainty plots with $95 \%$ confidence intervals, posterior parameter density distributions, values of dynamic global sensitivity (SRC) and Goodness-of-fit for linear regression $\left(\mathrm{R}^{2}\right)$ computed for SBH, TSS bottom and side concentration state-variables. 


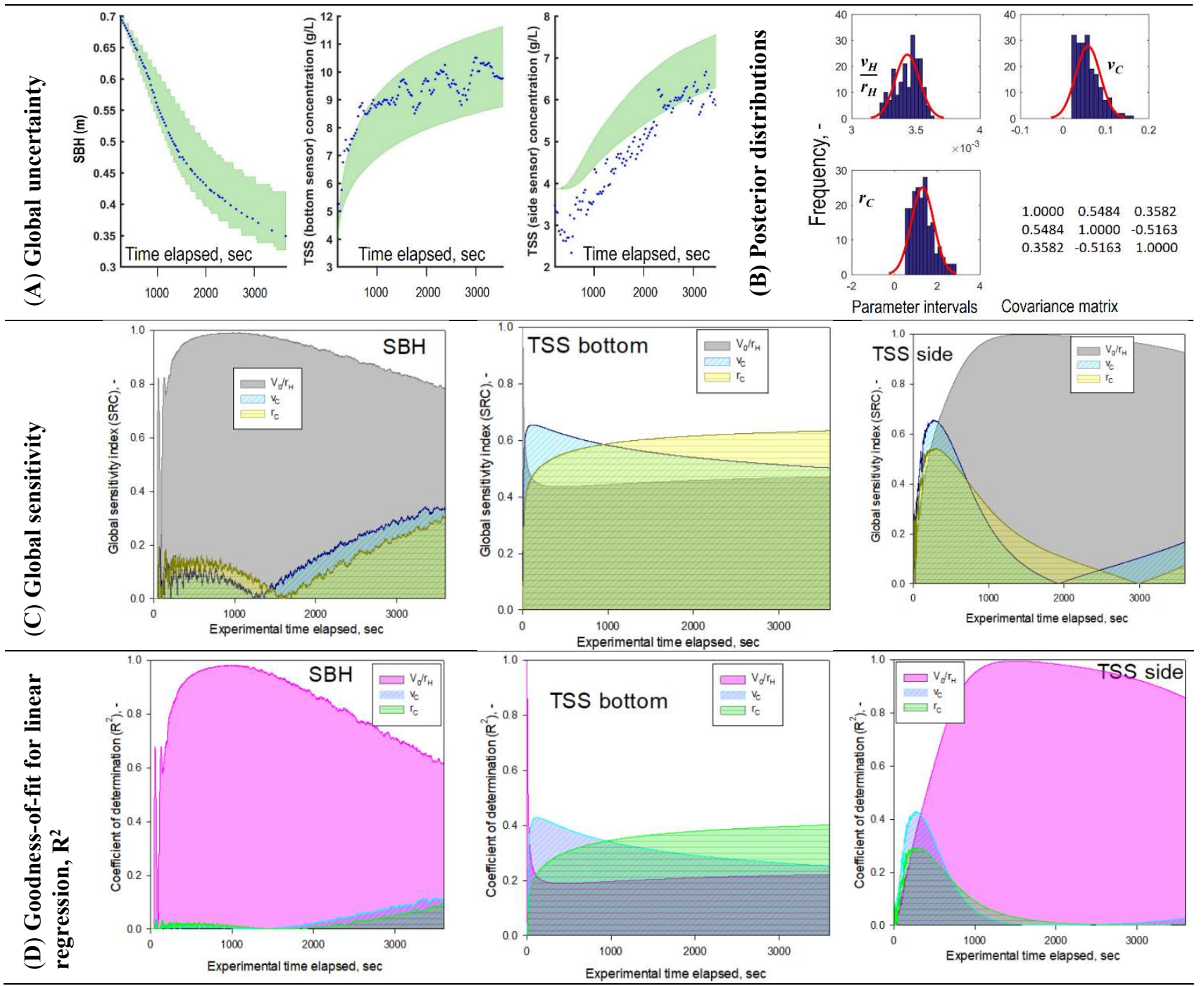

1126

1127

1128

1129

1130

1131

1132

1133

1134

1135

1136

1137

1138

Figure S12. Model validation using data obtained with filamentous bulking solids - measured and simulated data for activated sludge collected in Avedøre WRRF using the new hinderedcompression process model; Initial solid concentration: $3.9 \mathrm{~g} \mathrm{~L}^{-1}$; Proposed/a priori probability ranges: $v_{0} / r_{H}=[0.0030 .004] ; v_{C}=\left[\begin{array}{ll}0.01 & 0.2\end{array}\right] ; r_{C}=\left[\begin{array}{ll}0.13\end{array}\right]$; Global uncertainty plots with $95 \%$ confidence intervals, posterior parameter density distributions, values of dynamic global sensitivity (SRC) and Goodness-of-fit for linear regression $\left(\mathrm{R}^{2}\right)$ computed for SBH, TSS bottom and side concentration state-variables. 